\title{
Development of Eco-Friendly Cement Using a Calcium Sulfoaluminate Expansive Agent Blended with Slag and Silica Fume
}

\author{
Taewan Kim ${ }^{1}\left(\mathbb{D}\right.$, Ki-Young Seo $^{2}$, Choonghyun Kang ${ }^{3, *(D)}$ and Tak-Kee Lee ${ }^{4}$ \\ 1 Department of Civil Engineering, Pusan National University, Busan 46241, Korea; ring2014@naver.com
2 HK Engineering and Consultants, Busan 46220, Korea; aricari@hanmail.net
3 Department of Ocean Civil Engineering, Gyeongsang National University, Tongyeong 53064, Korea
4 Department of Naval Architecture and Ocean Engineering, Gyeongsang National University,
Tongyeong 53064, Korea; tklee@gnu.ac.kr
Correspondence: chkang@gnu.ac.kr; Tel.: +82-55-772-9124
}

check for updates

Citation: Kim, T.; Seo, K.-Y.; Kang, C.; Lee, T.-K. Development of Eco-Friendly Cement Using a Calcium Sulfoaluminate Expansive Agent Blended with Slag and Silica Fume. Appl. Sci. 2021, 11, 394. https://doi.org/10.3390/app11010394

Received: 7 December 2020 Accepted: 22 December 2020 Published: 4 January 2021

Publisher's Note: MDPI stays neutral with regard to jurisdictional clai$\mathrm{ms}$ in published maps and institutional affiliations.

Copyright: (C) 2021 by the authors. Licensee MDPI, Basel, Switzerland. This article is an open access article distributed under the terms and conditions of the Creative Commons Attribution (CC BY) license (https:// creativecommons.org/licenses/by/ $4.0 /)$.
Abstract: This is an experimental study on the development of a low-carbon, eco-friendly cement containing a calcium sulfoaluminate expansive agent (CSAe), slag, and silica fume (SF). The cement to be developed has a low water/binder ratio $(w / b)$ of 0.5 and is designed to be used for structural purposes, with focus on its mechanical performance. CSAe, slag, and SF were mixed at various mixing ratios. The main hydration product of the slag-based CSAe cement in the experiment was ettringite. Substituting less than $30 \%$ of CSAe showed a sufficient level of mechanical performance; that is, the material could be used as structural cement. SF controlled the excessive expansion of CSAe. However, since the developed slag-CSAe-SF cement has low early age (1 d) strength, follow-up research is needed for improvement.

Keywords: calcium sulfoaluminate; slag; silica fume; eco-friendly

\section{Introduction}

Calcium sulfoaluminate (CSA) cement is attracting attention as an ecofriendly cement that reduces $\mathrm{CO}_{2}$ emissions during manufacturing compared with ordinary Portland cement (OPC) [1-4]. Many previous studies show that CSA clinker with various ratios of calcium sulfate can be used to control the setting time, early and late strength, expandability, and volume stability of cement [5]. The main constituent of CSA clinker is ye'elimite $\left(\mathrm{C}_{4} \mathrm{~A}_{3} \overline{\mathrm{S}}\right)[5,6]$ (hereafter, cement chemistry shorthand notation will be used: $\mathrm{C}=\mathrm{CaO}, \mathrm{S}$ $=\mathrm{SiO}_{2}, \mathrm{~A}=\mathrm{Al}_{2} \mathrm{O}_{3}, \overline{\mathrm{S}}=\mathrm{SO}_{3}, \mathrm{H}=\mathrm{H}_{2} \mathrm{O}, \mathrm{F}=\mathrm{Fe}_{2} \mathrm{O}_{3}$, and $\mathrm{M}=\mathrm{MgO}$ ). The ye'elimite forms ettringite ( $\mathrm{AFt} ; \mathrm{C}_{6} \mathrm{AS}_{3} \mathrm{H}_{32}$ ), which is the main hydration product and plays an important role in the cement's mechanical and expansion properties [7]. For binary cement mixed with CSA and OPC, CSA has an important influence on the early hydration reaction and mechanical properties (within $24 \mathrm{~h}$ ), and OPC plays a dominant role thereafter [8]. Many previous studies focused on the expansion properties of CSA clinker or CSA cement [9-12]. In recent years, research has expanded on the control of the expansion and contraction properties of cement and multicomponent binders in which CSA and various cementitious materials are mixed. Various studies on the properties of cement mixed with CSA have been published.

Sirtoli et al. [13] conducted a study on shrinkage and creep for three concrete mixtures: pure CSA, portland-limestone cement, and a blend of the two (50:50 ratio by mass). They argued that the shrinkage and creep analysis model developed for Portland cement concrete currently in use is not suitable for application to Portland-CSA-based concrete because the main input data are based on compressive strength. Mehdipour and Khayat [14] conducted an experiment on the effect of a shrinkage-reducing admixture (SRA) or lightweight sand (LWS) on the expansion/contraction and compressive strength properties of an OPC-CSA 
system. The LWS or SRA had a significant effect on shrinkage and expansion properties compared with the OPC-CSA mixture alone. In particular, the use of SRA and LWS together in an OPC-CSA-based system improved performance while reducing the required wet hardening period. Chen et al. [15] reviewed the effects of an SRA and CSA cement on OPCbased high-strength strain-hardening cementitious composites on the shrinkage reduction and mechanical properties of the cement under various conditions. SRA reduced shrinkage, CSA affected the degree of hydration and setting time, and both SRA and CSA reduced the mechanical strength. Shen et al. [16] conducted a study on the volume stability of a CSA-CaO-based expansive agent (CSA-CaO EA) on ultra-high-performance concrete. They explained that low $w / b$ and dense microstructure are among the factors hindering the expansion effect of the CSA-CaO EA. Zhang et al. [17] studied the effect of CSA cement on the early properties and hydration of Portland cement. Zhang et al. [18] examined the manufacture of precast concrete at ambient temperatures using the Portland-CSA cement system. The CSA clinker or CSA cement has been published in a number of studies on properties based mainly on OPC.

In addition, regarding the characteristics of CSA, Li et al. [19] studied hydrates and porosity according to curing temperature and relative humidity $(\mathrm{RH})$. According to their report, the hydration products and pore characteristics of CSA cement depend on the curing conditions. There are also microstructural studies on the $\mathrm{AH}_{3}$ phase of the AFt- $\mathrm{AFm}-\mathrm{AH}_{3}$ hydration product system in CSA cement [20]. The effect of water and gypsum content on CSA-belite cement paste has also been explored [21]. In addition, research results on the effect of alkalis content on the hydration of CSA cement have been reported [22].

There have also been characterization studies on CSA mixtures with various admixtures. Ke et al. [23] studied the rheological behavior of CSA cement paste for various supplementary cementitious materials. According to their report, silica fume (SF) significantly reduced the maximum shear stress and plastic viscosity of the CSA cement paste and increased the yield stress. The combination of fly ash and slag mitigated the negative effects of the increase in the yield stress of the paste due to SF. The plastic viscosity of the CSA cement paste increased significantly with decreasing water/cement ratio $(w / c)$. A study on the tendency of compressive strength in the 1-year-long term of CSA cement mixed with OPC, pulverized fuel ash (PFA), and ground granulated blast furnace slag (GGBS) was also reported [24]. Their findings showed that increasing the CSA cement content with the same total binder content increased the early age strength. However, when only CSA cement and PFA or GGBS were combined, the compressive strength decreased significantly at later ages in the absence of OPC. In a study, the authors performed experiments in which CSA was applied to alkali-activated fly ash cement, and the resulting properties were compared with those of portland cement [25].

Recently, there have also been studies using CSAes. Winnefeld and Lothenbach [26] stated that a high $w / b$ of about 0.8 is required for the complete hydration reaction needed by CSAe to form ettringite. Cheung and Leung [9] investigated the effect of CSAes on the drying shrinkage of high-strength fiber-reinforced cementitious composites prepared with various $w / b$ values. The result indicated that a higher $w / b$ was more effective in compensating for the shrinkage of the mixtures caused by the mixing of CSA. Jun et al. [27] presented a study on the hydration properties of cement mixed with CSAe and red mud. CSA clinker or CSA cement was studied for its mechanical properties, hydration reactions and mechanisms, expansion/shrinkage properties, and microstructures, with focus on studies mixed with OPC.

The purpose of this study is to perform a basic experiment about the development of a low-carbon, eco-friendly cement that comprises a mixture of CSAe and slag and does not use OPC. CSAe and SF were substituted for slag mass. For CSAe, the substitution percentages were $10 \%, 20 \%$, and $30 \%$, and those for SF were $0 \%, 5 \%$, and $10 \%$. Nine mixtures were tested. The compressive strength, $\mathrm{X}$-ray diffraction (XRD), scanning electron microscopy (SEM), thermogravimetry (TG)/derivative TG (DTG), mercury intrusion porosimetry (MIP), and dry shrinkage up to $91 \mathrm{~d}$ were measured. The cement to be devel- 
oped must exhibit the mechanical performance required for structural use. The mechanical properties, hydration products, and drying shrinkage were analyzed according to the mixing ratio of CSAe, slag, and SF. The findings can be used as data for the development of cement that can replace OPC.

\section{Materials and Methods}

\subsection{Materials}

The utilized CSAe was white powder with a density of $2.88 \mathrm{~g} / \mathrm{cm}^{3}$, fineness of $4310 \mathrm{~cm}^{2} / \mathrm{g}$, and loss on ignition of $2.5 \%$. The compressive strengths of CSAe at 1,3 , 7 , and $28 \mathrm{~d}$ were $5.0,16.2,21.8$, and $32.4 \mathrm{MPa}$, and the length change rates at 7, 14, 21, and $28 \mathrm{~d}$ were $0.031 \%, 0.005 \%,-0.001 \%$, and $-0.008 \%$. In addition, the initial setting time was $205 \mathrm{~min}$, and the final setting time was $408 \mathrm{~min}$.

The slag had a fineness of $4200 \mathrm{~cm}^{2} / \mathrm{g}$, density of $2.81 \mathrm{~g} / \mathrm{cm}^{3}$, and loss on ignition of $1.73 \%$. SF had a density of $1.97 \mathrm{~g} / \mathrm{cm}^{3}$, fineness of $22,000 \mathrm{~cm}^{2} / \mathrm{g}$, and loss on ignition of $0.56 \%$. The components of CSAe, slag, and SF, as determined through X-ray fluorescence analysis, are shown in Table 1. XRF was measured with an XRF-1800 instrument (Shimadzu, -Kyoto, Japan) using dried powder. The $\mathrm{X}$-ray tube is $4 \mathrm{~kW}$ with a thin window (Rh-Ka) and the output stability is $\pm 0.005 \%$. Figure 1 shows the results of the XRD analysis of CSAe used in the study.

Table 1. Chemical properties of materials.

\begin{tabular}{cccccccc}
\hline & \multicolumn{7}{c}{ Chemical Components (\%) } \\
\hline & $\mathbf{S i O}_{2}$ & $\mathbf{A l}_{2} \mathbf{O}$ & $\mathbf{F e}_{2} \mathbf{O}$ & $\mathbf{M g O}$ & $\mathbf{C a O}$ & $\mathbf{K}_{\mathbf{2}} \mathbf{O}$ & $\mathbf{S O}_{3}$ \\
\hline Slag & 34.87 & 10.64 & 0.81 & 3.29 & 44.78 & 0.57 & 4.95 \\
SF & 96.58 & 0.72 & 0.42 & 0.25 & 0.37 & 0.69 & - \\
CSAe & 3.96 & 14.13 & 0.29 & 1.16 & 50.26 & - & 30.18 \\
\hline
\end{tabular}

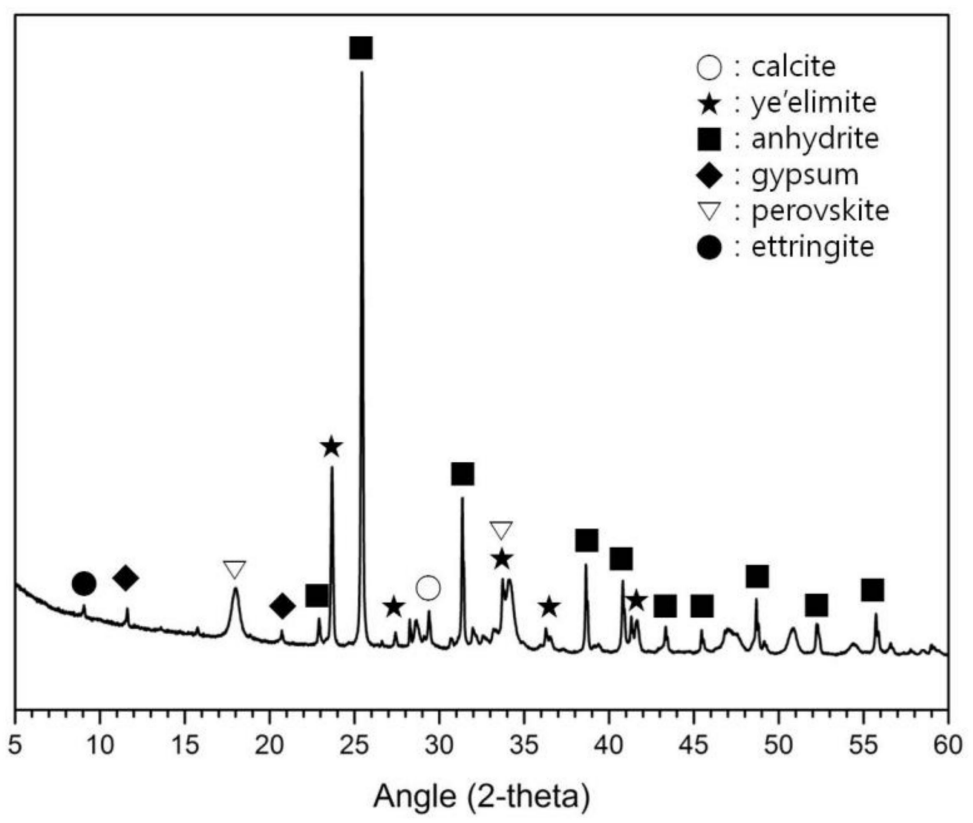

Figure 1. X-ray fluorescence analysis of CSAe.

\subsection{Experiments}

The water/binder ratio $(w / b)$ of the slag-CSAe-SF mixture was 0.50 . The mixtures of the paste were prepared in nine batches with the mixing proportions listed in Table 2. 
Table 2. Mix properties.

\begin{tabular}{cccc}
\hline \multirow{2}{*}{ Level } & \multicolumn{3}{c}{ Mix Ratio (wt.\%) } \\
\cline { 2 - 4 } & Slag & SF & CSAe \\
\hline G90F0C10 & 90 & 0 & 10 \\
G85F5C10 & 85 & 5 & 10 \\
G80F10C10 & 80 & 10 & 10 \\
\hline G80F0C20 & 80 & 0 & 20 \\
G75F5C20 & 75 & 5 & 20 \\
G70F10C20 & 70 & 10 & 20 \\
\hline G70F0C30 & 70 & 0 & 30 \\
G65F5C30 & 65 & 5 & 30 \\
G60F10C30 & 60 & 10 & 30 \\
\hline
\end{tabular}

The paste mixtures were blended according to ASTM C305 [28]. After being mixed, the samples were stored for $24 \mathrm{~h}$ at an $\mathrm{RH}$ of $95 \% \pm 5 \%$ and a temperature of $23^{\circ} \mathrm{C} \pm 1{ }^{\circ} \mathrm{C}$. The molds were then removed, and the mixtures were kept in a chamber under the same humidity and temperature conditions until the age of the measurement.

For the compressive strength tests, a mold sized $50 \mathrm{~mm} \times 50 \mathrm{~mm} \times 50 \mathrm{~mm}$ was used, and the measurement method was ASTM C109 [29]. The drying shrinkage was measured according to ASTM C596 [30] using a 40-mm $\times 40-\mathrm{mm} \times 160-\mathrm{mm}$ mold, and the length change was measured once every $7 \mathrm{~d}$ up to $91 \mathrm{~d}$ of aging.

Samples were prepared for XRD measurements by immersing fractured pieces of the specimen in acetone for $12 \mathrm{~h}$. They were then stored in a vacuum desiccator for $24 \mathrm{~h}$ before grinding. XRD measurements were obtained by passing each sample through a No. 200 $(75 \mu \mathrm{m})$ sieve. The measurements were recorded with a Panalytical $X^{\prime}$ Pert $^{3}$ (PANalytical, Almelo, The Netherlands), and analysis was performed with the HighScore Plus software.

MIP (AutoPore IV, Micromeritics, Norcross, GA, USA) measurements were obtained on $28 \mathrm{~d}$ of the experiment to measure the distribution of pores inside the specimen and their characteristics. The MIP measurement and 5-mm $\times 5-\mathrm{mm} \times 5-\mathrm{mm}$ cubic pieces were obtained from the central inner part of the hardened samples. They were immersed in acetone for $12 \mathrm{~h}$ to prevent further hydration. After $12 \mathrm{~h}$, the samples were dried in a vacuum desiccator for $24 \mathrm{~h}$ to eliminate any residual acetone inside the samples. The contact angle, surface tension, and density of $\mathrm{Hg}$ were assumed to be $130^{\circ}, 485 \mathrm{dyn} / \mathrm{cm}$, and $13.534 \mathrm{~g} / \mathrm{mL}$, respectively. The pore size distributions were measured with pore diameters ranging from 0.003 to $336 \mu \mathrm{m}$.

SEM (SUPRA ${ }^{\mathrm{TM}} 40$, Zeiss, Oberkochen, Germany) with energy-dispersive X-ray spectroscopy (EDS) was employed to take secondary electron (SEs) for the 28-d specimens. After the compressive strength measurement, the SEM sample was fractured; the broken pieces were immersed in acetone for $24 \mathrm{~h}$ and then dried in a vacuum desiccator for $24 \mathrm{~h}$. The dried broken pieces were coated with platinum before measurement. Representative SE images of the microstructures were captured at $\times 5000$ in high vacuum mode using an accelerating voltage of $15 \mathrm{kV}$ and a working distance of 9.8-10 mm. TG and DTG analyses were performed on 3-d- and 28-d-aged samples using a DSC 800 thermal analyzer (Perkin Elmer, Massachuestts, USA) and were measured at $30-900{ }^{\circ} \mathrm{C}$ at increments of $20^{\circ} \mathrm{C} / \mathrm{min}$ in a $\mathrm{N}_{2}$ gas environment.

\section{Results and Discussion}

\subsection{Compressive Strength}

Figure 2 shows the results of the compressive strength measurements at each age. The compressive strength tended to increase with age. This means that the hydration of slag and CSAe continued to progress with age. Moreover, regardless of the substitution rate of CSAe, the compressive strength improved as the substitution rate of SF increased to $0 \%, 5 \%$, and $10 \%$. However, the $1 \mathrm{~d}$ strength of all CSAe mixed samples showed a low 
value of less than $7 \mathrm{MPa}$. Therefore, subsequent studies should be conducted to improve the early age $(1 \mathrm{~d})$ compressive strength of the proposed material so that it can be used as structural concrete.

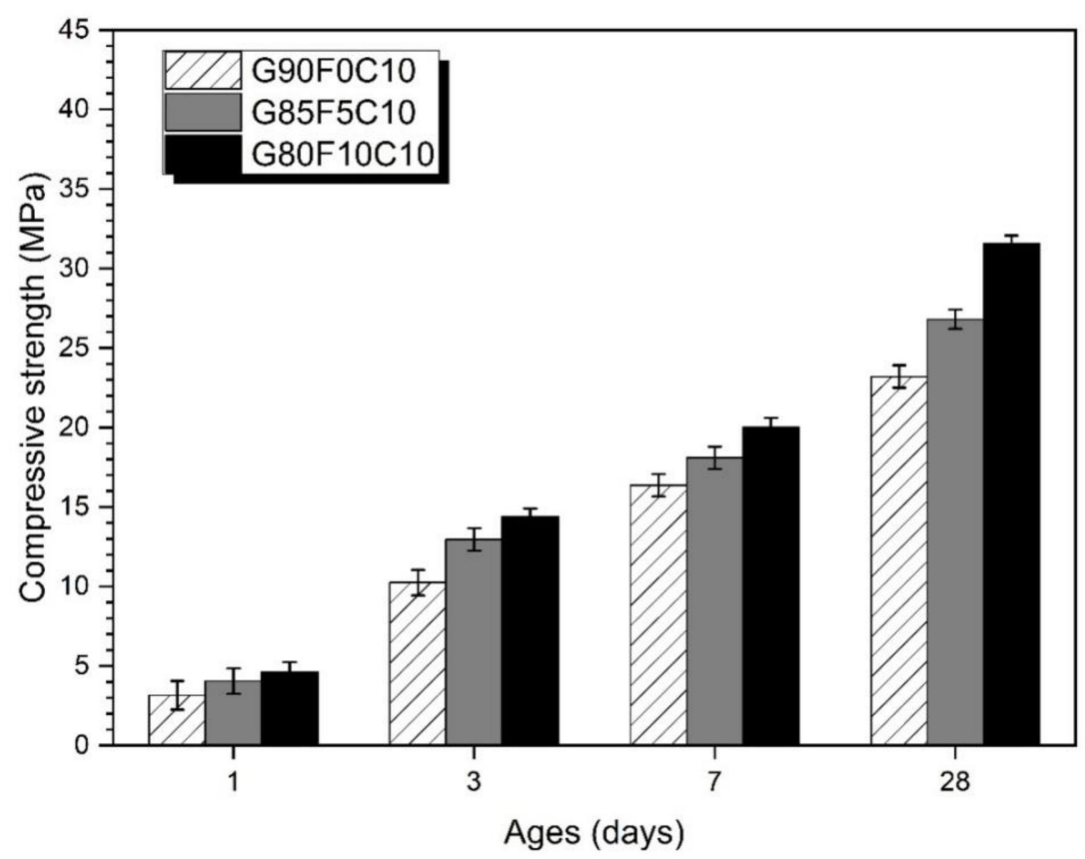

(a)

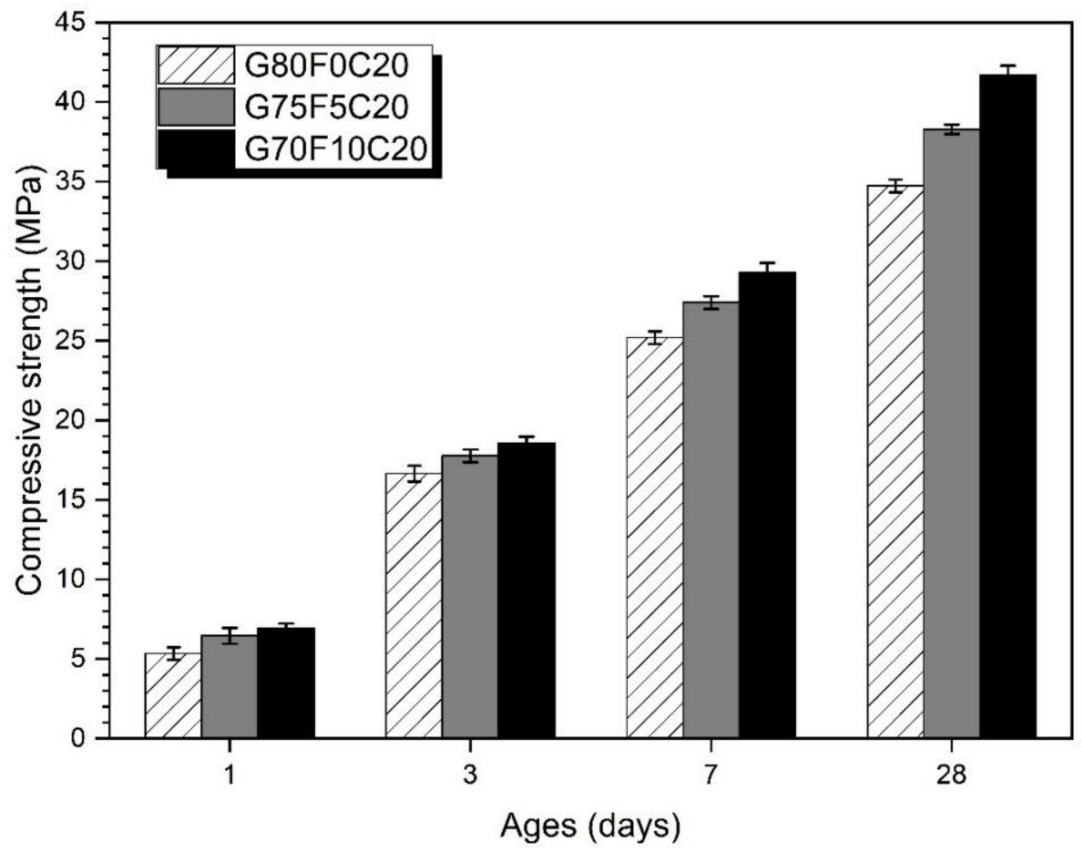

(b)

Figure 2. Cont. 


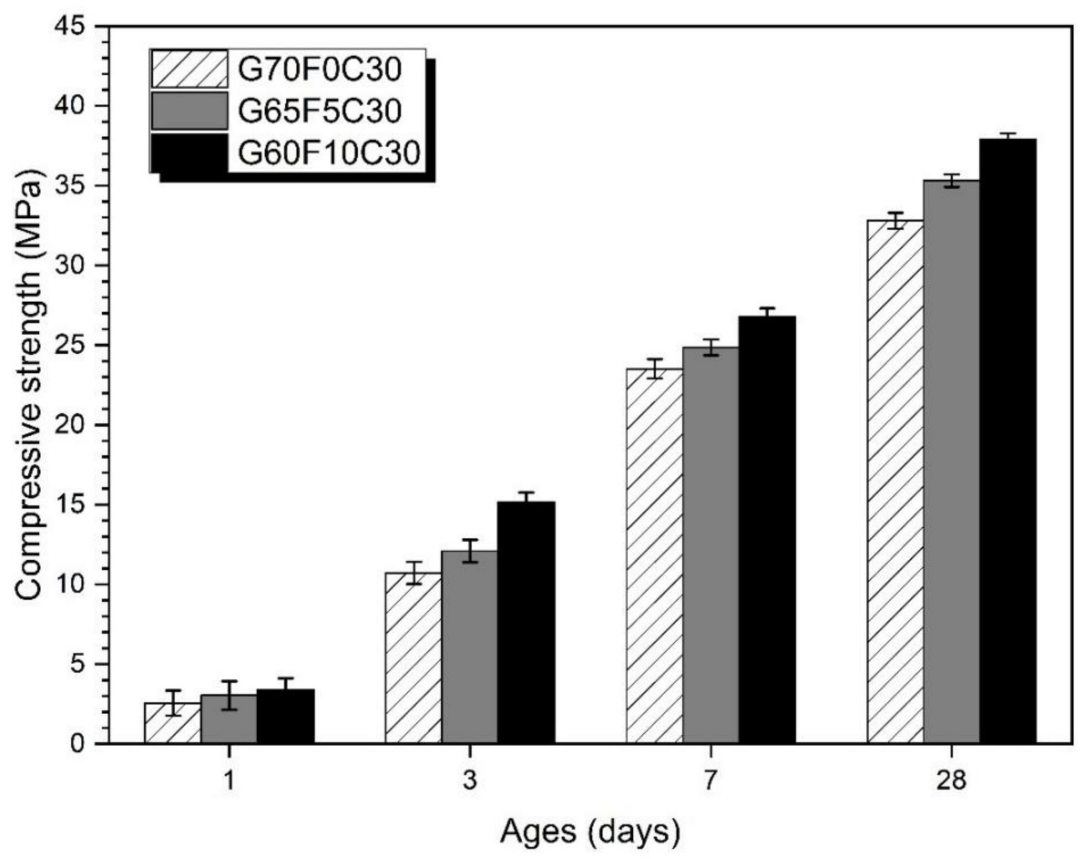

(c)

Figure 2. Compressive strengths of slag-SF-CSAe cement pastes, (a) 10\% CSAe samples, (b) 20\% CSAe samples, and (c) $30 \%$ CSAe samples.The.

In the $10 \%$ CSAe samples, the $28 \mathrm{~d}$ compressive strengths at $0 \%, 5 \%$, and $10 \%$ SF were 23.2, 26.8, and 31.6 MPa, respectively. Those for the 20\% CSAe samples were 34.7, 38.3, and 41.7 $\mathrm{MPa}$, and those for the 30\% CSAe samples were 32.8, 35.3, and 37.87 MPa, respectively. The highest compressive strength was measured on a $20 \%$ CSAe sample. In the 30\% CSAe samples, the excessive expansion effect at the early age of CSAe may have caused cracks on the specimen surface and interior, thereby inhibiting the increase in strength.

The compressive strength results in Figure 2 show that the strength-improving effect of increasing the CSAe replacement rate was consistent with the experimental results of OPC mixed with CSA reported by previous studies [31,32]. However, compared with CSA mixed with OPC, the CSAe used in this study had a specific substitution ratio that affected the increase in compressive strength due to its higher expandability.

The decrease in compressive strength at 30\% CSAe, which was increased to $20 \%$ CSAe, can be attributed to excessive expansion. The CSAe showed high expansibility in the early hydration stage before hardening. As the substitution ratio of CSAe increased, $\mathrm{C}_{4} \mathrm{~A}_{3} \overline{\mathrm{S}}$ increased, and the expansion action of $\mathrm{C}_{4} \mathrm{~A}_{3} \overline{\mathrm{S}}$ also increased. $\mathrm{C}_{4} \mathrm{~A}_{3} \overline{\mathrm{S}}$ promotes setting with its rapid early hydration reaction [33]. This quick setting reduces workability and leads to a surfeit of reaction material, which forms pores and weakens the matrix. Another reason may be the formation of voids around the CSAe particles due to the rapid formation of ettringite during the early hydration step [18,33-35]. As shown in the XRD analysis, the highest ettringite peak was observed at 30\% CSAe. It can be presumed that ettringite, which was initially formed in a large amount, covered the slag particles and played a role in preventing the hydration reaction [36,37].

A large amount of mixing water is required for $\mathrm{C}_{4} \mathrm{~A}_{3} \overline{\mathrm{S}}$ to be completely hydrated. When the $w / b$ is less than $0.6, \mathrm{C}_{4} \mathrm{~A}_{3} \overline{\mathrm{S}}$ does not fully hydrate and causes excessive expansion [5]. Therefore, this study's $w / b$ of 0.5 was not sufficient for the complete hydration of $\mathrm{C}_{4} \mathrm{~A}_{3} \overline{\mathrm{S}}$. This excessive expansion affected the distribution and size of pores in the material, weakening the hardened samples. In addition to the insufficient water, the sulfates contained in the CSAe may have been a factor. In Minard et al. [38], an increase in sulfate ions indicated the effect of delayed hydration. In this study, increasing the replacement rate of CSAe increased the sulfate ions present. Increasing the replacement rate of CSAe 
also increased the amount of $\mathrm{C}_{4} \mathrm{~A}_{3} \overline{\mathrm{S}}$ found in the samples. However, unreacted $\mathrm{C}_{4} \mathrm{~A}_{3} \overline{\mathrm{S}}$ was left over because of the $w / b$, which was insufficient for $\mathrm{C}_{4} \mathrm{~A}_{3} \overline{\mathrm{S}}$ to sufficiently hydrate.

SF showed the effect of improving compressive strength in all the CSAe substitution mixtures considered. SF showed an improvement effect from the early age of $1 \mathrm{~d}$ compressive strength. It is believed that this contributes to the strength shape by forming a dense matrix due to the filler effect. The effect of improving the mechanical performance of SF is evident as the substitution rate of SF increases from $5 \%$ to $10 \%$.

In Figure 2, it can be seen that the compressive strength of $1 \mathrm{~d}$ was low regardless of the CSAe substitution rate, but increased significantly after $3 \mathrm{~d}$. Looking at the compressive strength ratio of $3 \mathrm{~d}$ to $1 \mathrm{~d}$, the G90F0C10, G85F5C10, and G80F10C10 of the $10 \%$ CSAe sample were $325.1 \%, 320.0 \%$, and $310.3 \%$. G80F0C20, G75F5C20, and G70F10C20 were $311.8 \%, 275.3 \%$, and $267.8 \%$, and G70F0C $30, \mathrm{~F} 65 \mathrm{~F} 5 \mathrm{C} 30$, and G60F10C 30 were $418.8 \%$, $397.7 \%$, and $444.9 \%$. The increase rate of compressive strength from $1 \mathrm{~d}$ to $3 \mathrm{~d}$ was the highest. Therefore, when looking at the rate of strength increase, it can be considered that the hydration delay of slag affects up to $3 \mathrm{~d}$. According to previous studies, CSA shows fast and high-strength values during its early ages. However, under the conditions of this study, the improvement in compressive strength of the early age of CSAe was delayed by about $3 \mathrm{~d}$. This may have been related to the high slag mixing ratio. Slow slag hydration affects strength development. Therefore, the hydration reaction of slag in early age may have delayed the strength development. In future studies, additional methods or admixtures should be used to promote the early age hydration of slag.

Table 3 shows the rate of change of the strength values of samples with and without SF. SF substitution showed the highest increase in compressive strength of $1 \mathrm{~d}$ in all CSAe substitution rates. It is believed that SF filling and nucleation promoting effects acted in the early hydration process. From Table 3 , it can be seen that the compressive strength improvement effect is further improved as the replacement rate of SF increases from $5 \%$ to $10 \%$.

Table 3. The rate of change in strength of with SF to without SF samples by measurement age

\begin{tabular}{cccccc}
\hline \multirow{2}{*}{ CSAe (\%) } & \multirow{2}{*}{ SF (\%) } & \multicolumn{4}{c}{ The Rate of Change in Strength (\%) } \\
\cline { 2 - 6 } & & $\mathbf{1 ~ d}$ & $\mathbf{3 ~ d}$ & $\mathbf{7 ~ d}$ & $\mathbf{2 8 ~ d}$ \\
\hline \multirow{2}{*}{10} & 5 & 128.6 & 126.6 & 120.6 & 112.5 \\
\cline { 2 - 6 } & 10 & 147.3 & 140.6 & 140.5 & 136.1 \\
\hline \multirow{2}{*}{20} & 5 & 120.8 & 106.7 & 108.7 & 110.3 \\
\cline { 2 - 6 } & 10 & 129.8 & 111.5 & 116.2 & 120.0 \\
\hline \multirow{2}{*}{30} & 5 & 118.8 & 112.8 & 105.7 & 107.7 \\
& 10 & 133.2 & 131.5 & 113.9 & 115.5 \\
\hline
\end{tabular}

\subsection{Hydration Products}

Figure 3 shows the XRD results for the analysis of the hydration products. The main hydration products of the slag-SF-CSAe cement were ettringite. As the substitution rate of CSAe increased, the ettringite and ye'elimite peak increased. As CSAe decreases from 30\% to $10 \%$, the ettringite peak gradually decreases, and it can be seen that the order of Figure $3 c>$ Figure $3 b>$ Figure $3 a$ decreases. It also shows that ye'elimite peak also decreases with ettringite. 


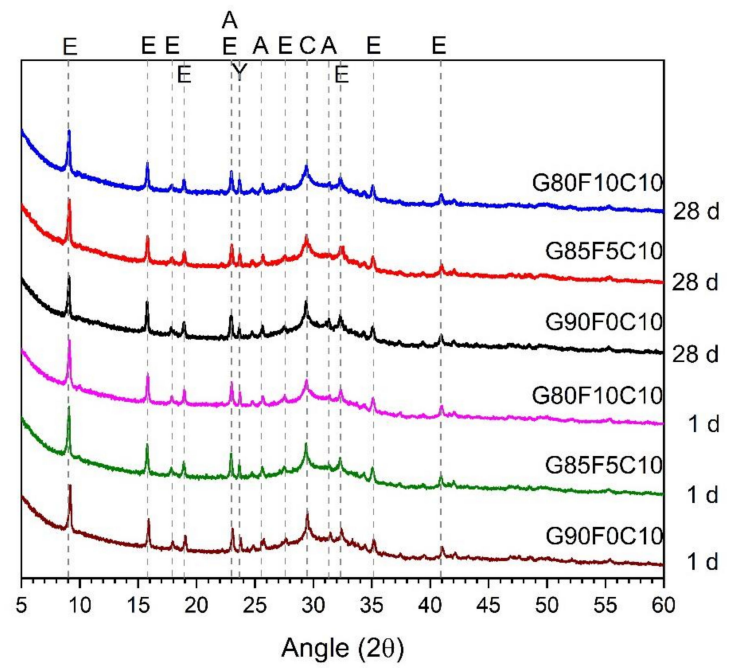

(a)

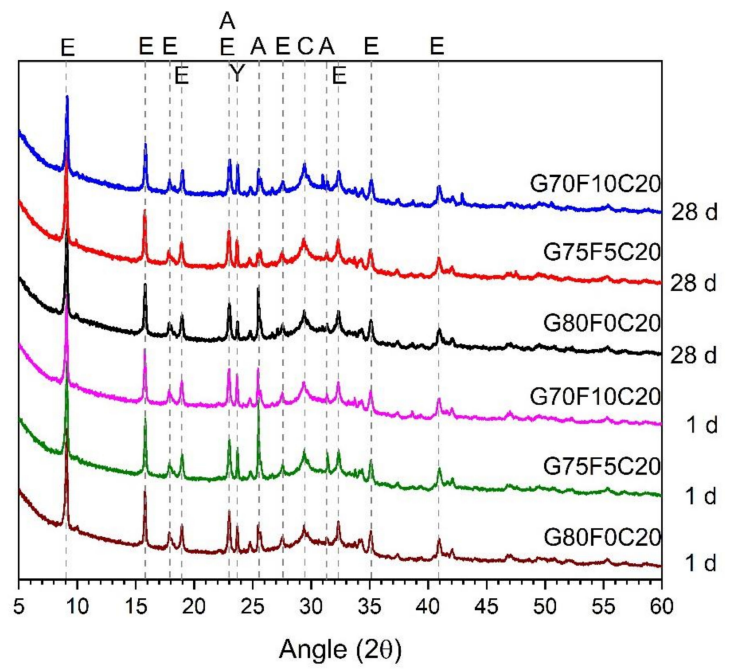

(b)

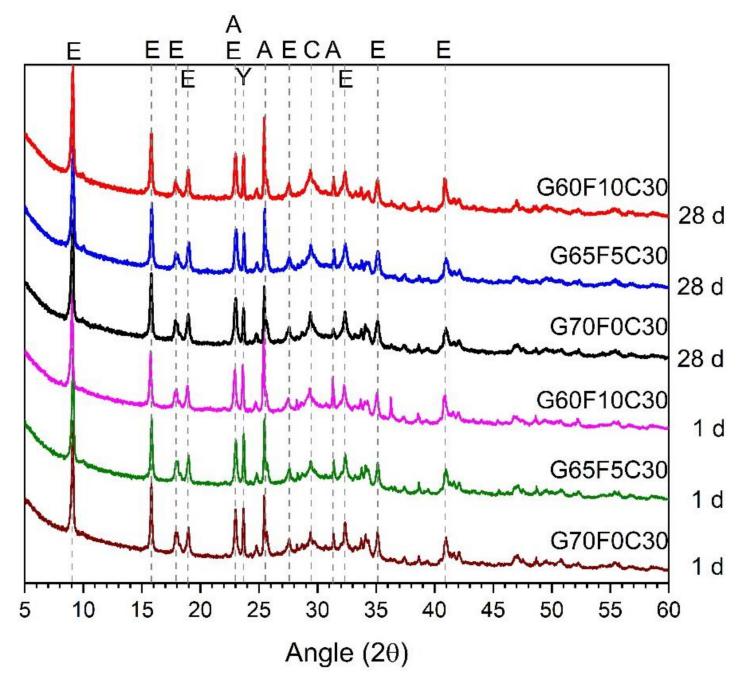

(c)

Figure 3. XRD results (a) 10\% CSAe at $1 \mathrm{~d}$ and $28 \mathrm{~d}$ (b) $20 \%$ CSAe at $1 \mathrm{~d}$ and $28 \mathrm{~d}$, (c) 30\% CSAe at $1 \mathrm{~d}$ and $28 \mathrm{~d}$, E: ettringite, A: anhydrite, Y: ye'elimite, C: C-S-H/calcite (overlap). 
The increase in CSAe promoted the production of ettringite, and the increase in ye'elimite confirmed the presence of dehydrated CSAe. However, changes in hydration products were not observed due to the presence or absence of SF and the substitution rate. In addition, the change in the peak of the C-S-H gel, the major hydration product of slag, was almost unchanged regardless of the substitution ratio of CSAe and SF. In Figure $3 a-C$, changes in the peaks of ettringite and C-S-H, which are major hydration products, were insignificant despite the increase in the SF substitution rate to $0 \%, 5 \%$, and $10 \%$.

According to previous studies, SF is formed by dense reaction products at the early age hydration stage of hydration reactions by a pozzolanic reaction with portlandite $[39,40]$. In Figure 3, no portlandite peak was observed regardless of the substitution ratio of CSAe. Unlike previous studies, this study did not use OPC, so there was no major source of portlandite.

Thus, no pozzolanic reaction of SF occurred. Portlandite is also consumed in the hydration of slag. In conclusion, the lack of portlandite affected the production of C-S-H gel by reducing the pozzolanic reaction of SF and hydration of slag. Therefore, the change in the C-S-H gel peak was very small compared with other hydration reactants.

Previous studies on CSA and the present study have certain differences. The XRD analysis in the current work did not identify strätlingite $\left(\mathrm{C}_{2} \mathrm{ASH}_{8}\right)$ in the hydration products. Strätlingite is observed at $w / c$ exceeding 0.6 or under sufficient moisture-supplymaintaining conditions, such as water curing [26,41]. Moreover, portlandite [26,42] and monosulfate $\left(\mathrm{C}_{4} \mathrm{~A} \overline{\mathrm{S}} \mathrm{H}_{12}\right)$ [26] were not detected in the present study. Previous studies are mostly about CSA cement mixed with CSA and OPC. By contrast, the present work did not use OPC. Therefore, the calcium, silicate, and aluminum supplied from OPC are not enough. In the case of slag, the formation of a relatively rich reactant was difficult due to the lower hydration reactivity of slag compared with OPC. In this study, some of the hydration reactants observed in previous studies on binders without OPC were not seen.

Previous studies have shown that fly ash is mostly a filler because it exhibits little reactivity in binary binders wherein it is mixed with CSA [43-45]. The slag in the current study showed low hydration reactivity in the binder of slag-CSAe-SF. However, the low hydration reactivity of slag was complemented by the substitution of SF. The strength of the material increased with the SF content for the same CSA replacement ratio, as shown in Figure 2.

The peak changes in the $1 \mathrm{~d}$ and $28 \mathrm{~d}$ hydration products in all the samples were highly similar in the XRD analysis. Therefore, thermal analysis, which is discussed in the next section, was performed to observe the changes in the hydration products.

\subsection{Pore Structures}

Figure 4 shows the results of the porosity analysis. MIP does not accurately represent the overall pore characteristics of a specimen but provides sufficient data for relative comparison $[46,47]$.

As the substitution ratio of CSAe increased, the number of pores decreased. This tendency was confirmed by the gradual decrease in the peak height of the graphs of G90F0C10 (Figure 4a), G80F0C20 (Figure 4b), and G60F0C30 (Figure 4c). In addition, in the samples with SF substitution, the graph is shifted to the left as a whole, and it can be seen that pores of smaller diameter are formed. In Figure 4, the samples with SF substitution showed a similar tendency; the peak of the graph decreased as the substitution ratio of CSAe increased. The increase in the amount of CSAe increased the production of $\mathrm{C}_{6} \mathrm{AS}_{3} \mathrm{H}_{32}$, which changed the pore structure by filling the pore interior. Thus, as more $\mathrm{C}_{6} \mathrm{AS}_{3} \mathrm{H}_{32}$ was produced, the number and size of the internal pores decreased. 


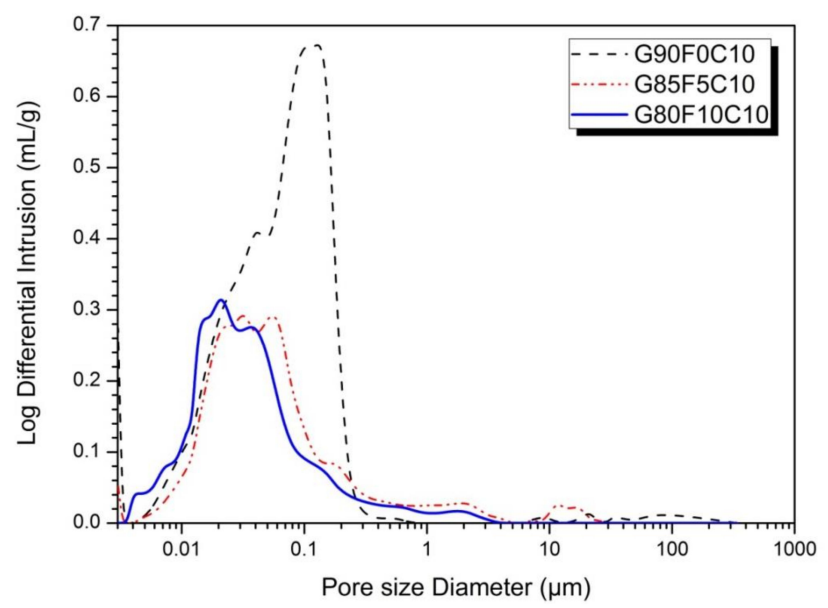

(a)

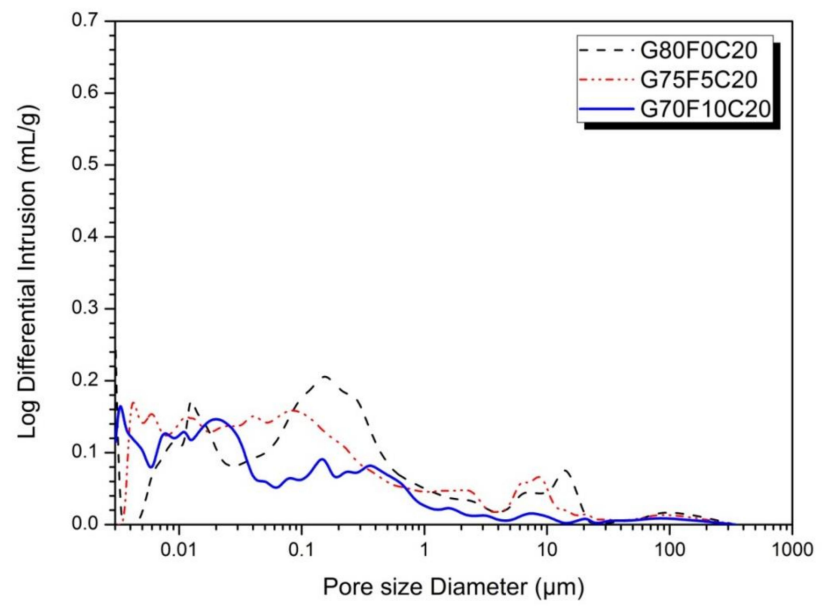

(b)

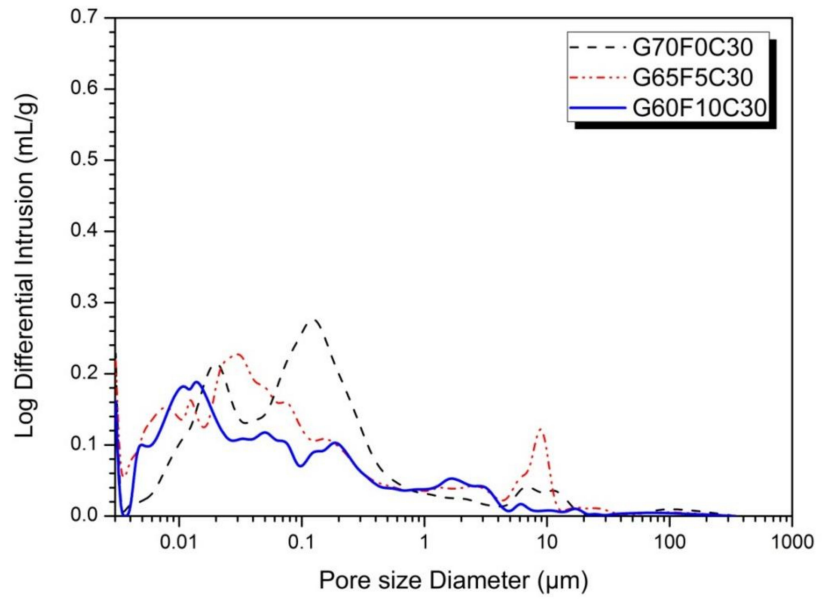

(c)

Figure 4. MIP results at 28 d, (a) 10\% CSAe, (b) 20\% CSAe, and (c) 30\% CSAe.

As stated in previous studies, CSA reduces the size and number of pores by the production of $\mathrm{C}_{6} \mathrm{~A}_{3} \mathrm{H}_{32}[6,41,42,45,48]$. This is consistent with the pore structure analysis results of the present study. In many studies on SF, the substitution of SF affected pore reduction due to filler effects [49] and pozzolanic reactions [39,40,50]. In addition, the use of SF makes the overall shape of the graph smaller and moves to the left, confirming that there is an effect of reducing pores. In Figure 4a, the graph of 10\% SF sample (G80F10C10) is shifted to the left more than 5\% (G85F5C10) and without-SF (G90F0C10). Similarly, in 
Figure $4 b, c, 10 \%$ SF samples (G70F10C20 and G60F10C30) showed that the graph shifted to the left. This shows the effect of matrix densification according to the substitution of SF. This densification effect can be seen to contribute to the improvement of compressive strength analyzed in Figure 2. In this study, however, no pozzolanic reaction occurred. Therefore, the pore diameter reduction shown in Figure 4 may have been due to the filler effect.

Figure 5 shows the total porosity for each sample. CSAe effectively reduces the size of pores by the production of ettringite in the pores. SF also has the effect of filling pores due to the size of the fine particles. Therefore, CSAe and SF can reduce the pore size as a whole. In Figure 5, the total porosity of the 20\% CSAe samples was the smallest, followed by those of the $10 \%$ CSAe and 30\% CSAe samples. When the substitution rate of CSAe was the same, the total porosity decreased, and the volume of pores smaller than $50 \mathrm{~nm}$ increased with the substitution rate of SF. This trend was seen in the $10 \%$ and $20 \%$ CSAe samples. However, the 30\% CSAe samples had a significantly higher total porosity than the 20\% CSAe samples. This is because the 30\% CSAe substitution rate caused cracks on the surface and in the interior due to excessive expansion, thereby reducing the accuracy of the pore analysis results.

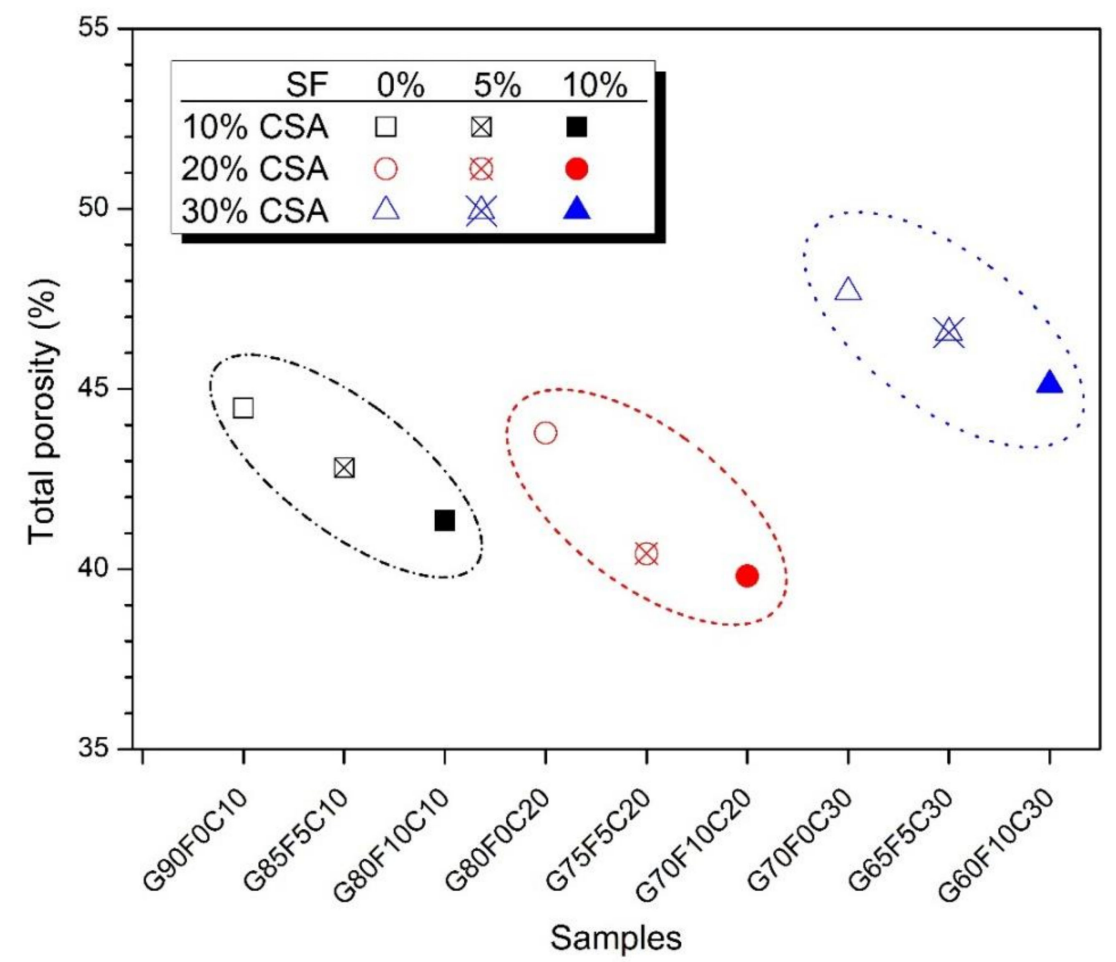

Figure 5. Total porosity for mixtures.

The results of Chaunsali and Mondal [51] revealed that OPC and 30\% CSAe cement increase porosity by excessive cracking. The total porosity results in Figure 5 showed similar trends in increasing the total porosity due to cracking at high CSAe substitution rates, as reported by Chaunsali and Mondal [51]. Therefore, in the range of the conditions considered in this study, $20 \%$ CSAe is the optimum mixing ratio for the improvement of compressive strength and the formation of a dense matrix.

A CSAe content of $30 \%$ may lead to excessive expansion, which inhibits the densification of the reaction products inside and outside a specimen. $\mathrm{C}_{4} \mathrm{~A}_{3} \overline{\mathrm{S}}$ also reduces workability due to early hydration reactions [33,52]. The increase in $C_{4} A_{3} \bar{S}$ accelerates the initial condensation [32], thereby reducing workability, lowering homogeneity, and causing many bubbles to form in the mixture. Increasing the SF replacement ratio also degrades workability, thus hindering the formation of the compact material. Therefore, the 
pore structure of the $30 \%$ CSAe samples did not show a smaller pore size and volume to those of the $20 \%$ CSAe samples. This means that the influence of excessive expansion due to the high CSAe substitution rate should be carefully considered when determining the composition ratio of slag-CSAe-SF cement.

\subsection{Microstructures}

Figure 6 shows the SEM images of the 10\% (Figure 6a), 20\% (Figure 6b), and 30\% CSAe samples (Figure $6 \mathrm{c}$ ) after $28 \mathrm{~d}$ of curing. Long, needle-shaped $\mathrm{C}_{6} \mathrm{~A}_{3} \mathrm{H}_{32}$ was observed in all samples. $\mathrm{C}_{6} \mathrm{AS}_{3} \mathrm{H}_{32}$ is a typical hydration reaction product found in previous studies involving CSA $[33,42,52,53] . \mathrm{C}_{6} \mathrm{AS}_{3} \mathrm{H}_{32}$ was observed in all samples, as shown in the XRD results in Figure 3. As illustrated in Figure 6, the length of $\mathrm{C}_{6} \mathrm{AS}_{3} \mathrm{H}_{32}$ varied according to the substitution ratio of CSAe. According to Figure 6a, the ettringite of $10 \%$ CSAe was about $1.5-\mu \mathrm{m}$ long. In the case of the $20 \%$ and $30 \%$ CSAe samples in Figure $6 \mathrm{c}, \mathrm{e}$, the $\mathrm{C}_{6} \mathrm{AS}_{3} \mathrm{H}_{32}$ length was increased to 2 and $3 \mu \mathrm{m}$, respectively. Therefore, increasing the substitution rate of CSAe increased the amount and length of $\mathrm{C}_{6} \mathrm{AS}_{3} \mathrm{H}_{32}$. This led to an increase in the amount of $\mathrm{C}_{4} \mathrm{~A}_{3} \overline{\mathrm{S}}$ as the substitution rate of CSAe increased, which promoted the formation and growth of fast $\mathrm{C}_{6} \mathrm{AS}_{3} \mathrm{H}_{32}[33,53]$. The increase in $\mathrm{C}_{4} \mathrm{~A}_{3} \overline{\mathrm{S}}$ as the substitution rate of CSAe increases is supported by the results of the XRD analysis in Figure 3.

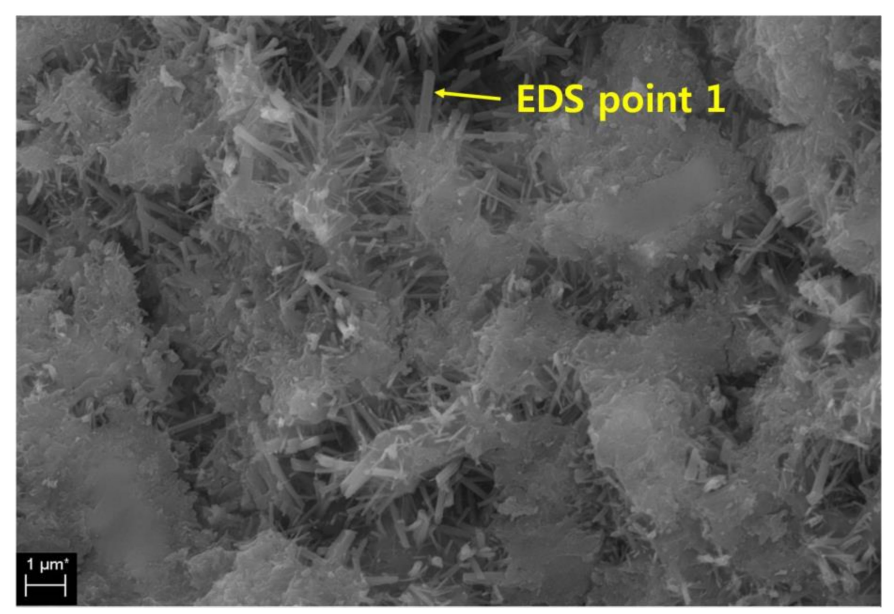

(a)

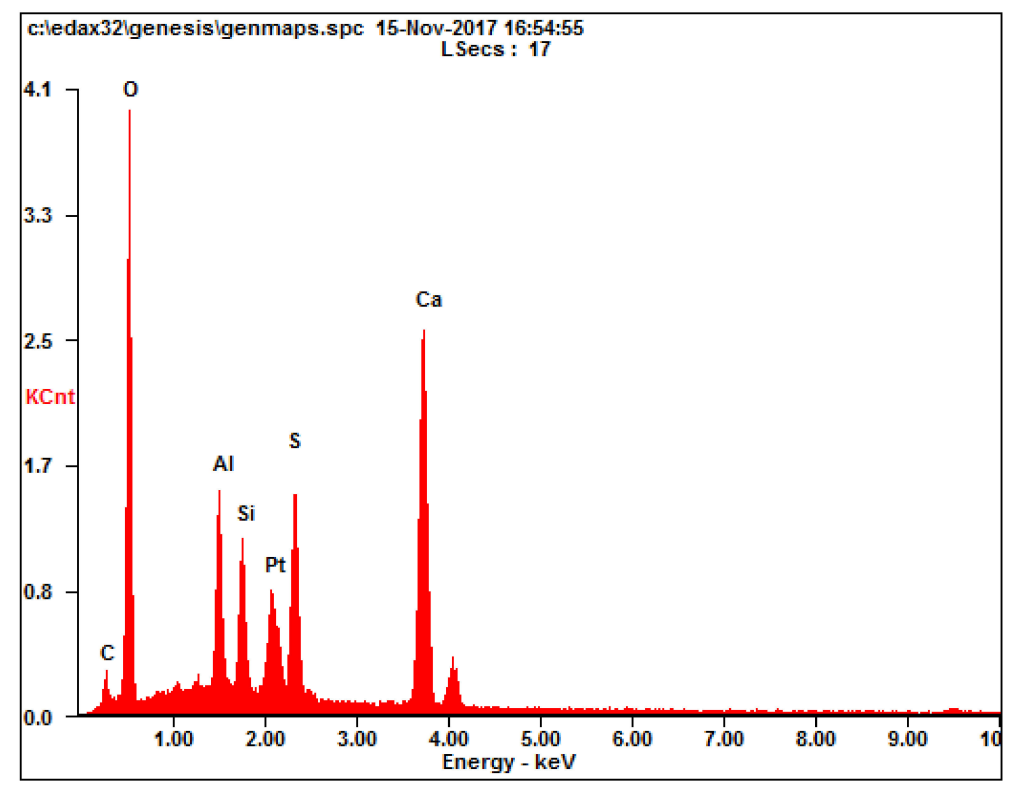

(b)

Figure 6. Cont. 


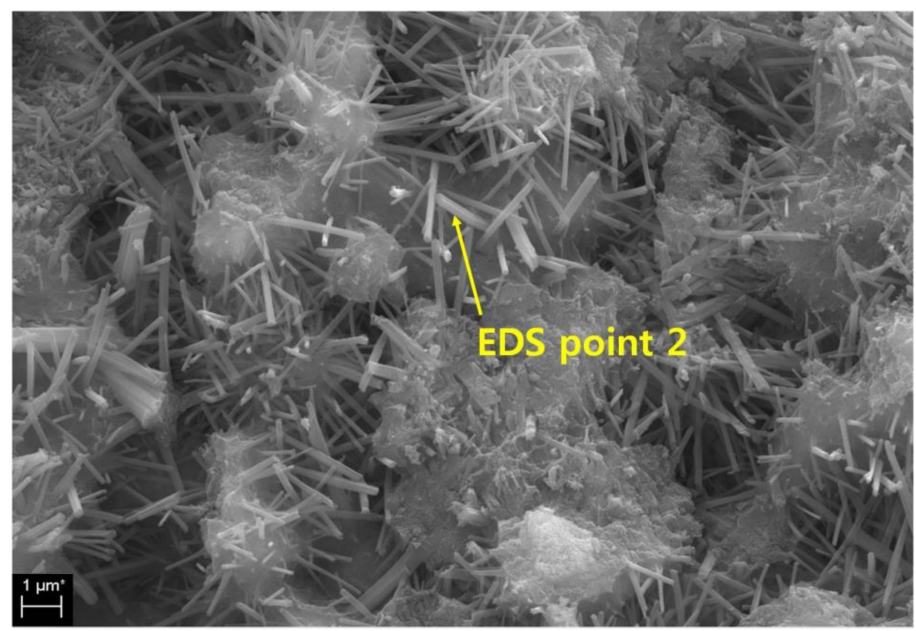

(c)

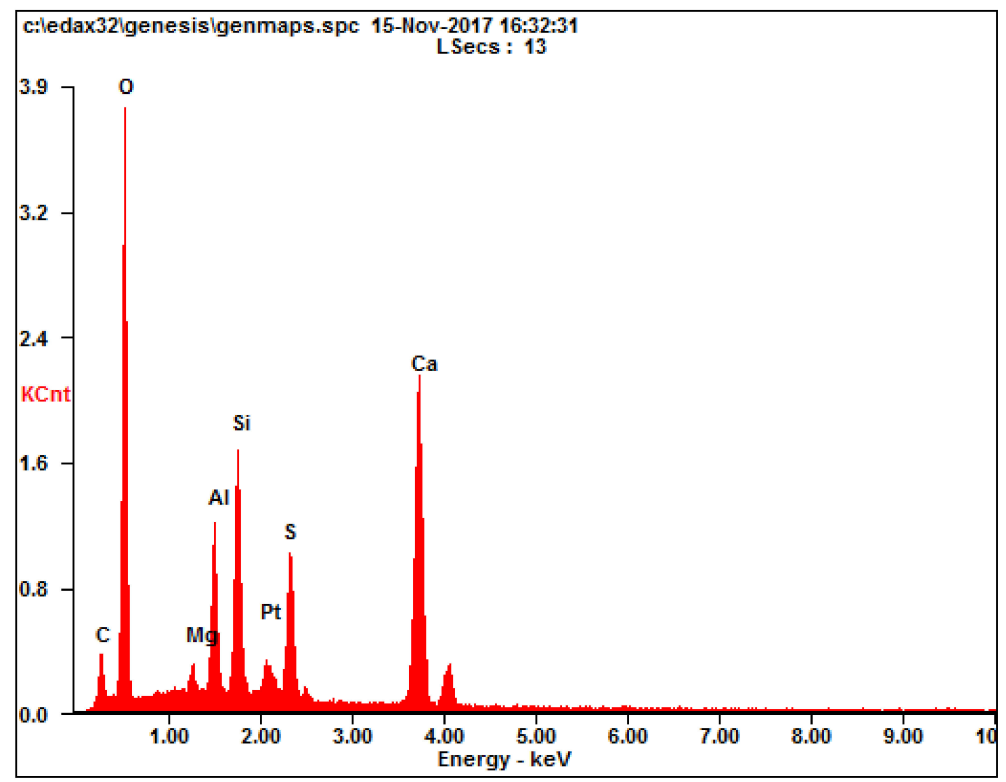

(d)

Figure 6. Cont. 


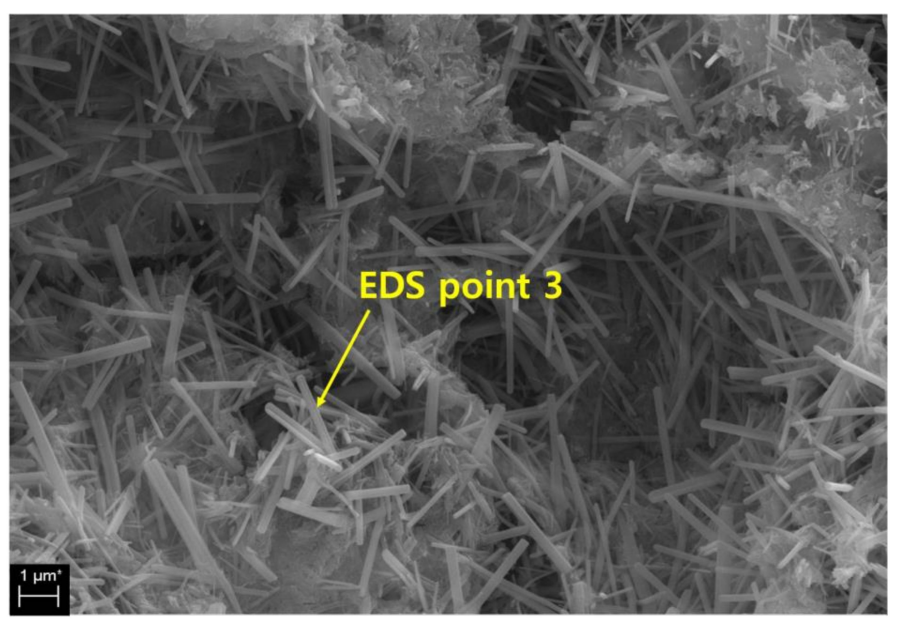

(e)

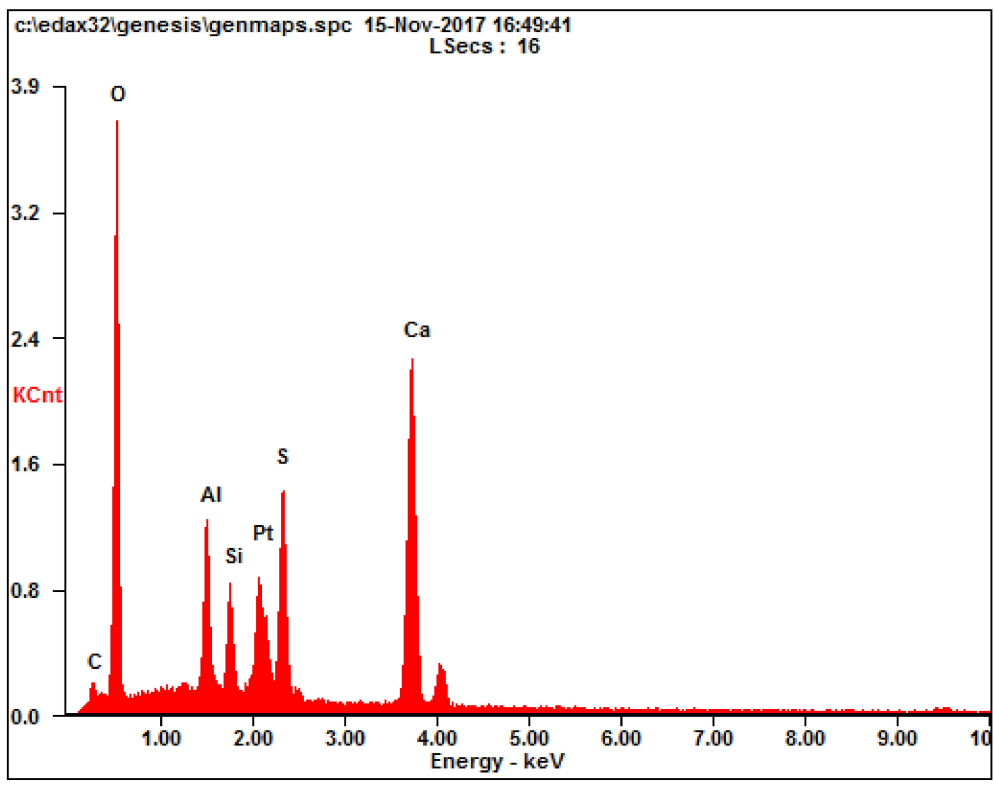

(f)

Figure 6. SEM images at 28 d, (a) G80F10C10, (b) EDS result of ettringite (EDS point 1), (c) G70F10C20, (d) EDS result of ettringite (EDS point 3), (e) G60F10C30, and (f) EDS result of ettringite (EDS point 3).

EDS analysis was performed on the $\mathrm{C}_{6} \mathrm{AS}_{3} \mathrm{H}_{32}$ in each SEM image, and the results are shown in Figure $6 \mathrm{~b}, \mathrm{~d}$,f. The EDS analysis results are consistent with the $\mathrm{C}_{6} \mathrm{AS}_{3} \mathrm{H}_{32}$ seen in previous studies on CSA [33]. The EDS analysis showed Si elements, which are not constituents of $\mathrm{C}_{6} \mathrm{AS}_{3} \mathrm{H}_{32}$. In samples not substituted with $\mathrm{SF}$, this phenomenon probably resulted from the intermixed ettringite crystals and amorphous $\mathrm{C}-\mathrm{S}-\mathrm{H}$ gel or from the appearance of $\mathrm{C}-\mathrm{S}-\mathrm{H}$ gel in the detecting range of the electron beam during EDS testing [33]. In the samples where SF is substituted, it is judged to be due to the influence of SF as well as the aforementioned cause.

Increasing the replacement rate of CSA increased the amount of $\mathrm{C}_{6} \mathrm{~A} \overline{\mathrm{S}}_{3} \mathrm{H}_{32}$ produced. This affected the mechanical properties of the specimen through pore filling and expansion. This is also confirmed by the increase of the ettringite peak in Figure 3 mentioned above and the thermal analysis of Figure 8, which will be mentioned later.

Therefore, the sample whose amount of $\mathrm{C}_{6} \mathrm{AS}_{3} \mathrm{H}_{32}$ increased with the substitution rate of CSAe showed a relatively high compressive strength. This is clearly indicated in the strength characteristics in Figure 4. Moreover, Figure 3 shows that the pore size and number of the CSA-substituted sample with increasing amounts of $\mathrm{C}_{6} \mathrm{AS}_{3} \mathrm{H}_{32}$ decreased. 
These strength enhancement and void reduction effects show synergistic effects as the $\mathrm{C}_{6} \mathrm{AS}_{3} \mathrm{H}_{32}$ produced by the hydration of CSAe increased with the SF substitution ratio. However, the experimental factors considered in this study were a low $w / b=0.5$ and high CSAe replacement rates. This can lead to excessive expansion and thus increased internal pores and cracks.

\subsection{Drying Shrinkage}

Figure 7 plots the drying shrinkage ratio against the substitution ratio of CSAe and SF. The drying shrinkage decreased as the CSAe substitution ratio increased from $10 \%$ to $30 \%$ (without SF). As shown in Figure 7c, the drying shrinkage of the 30\% CSAe sample was the least. Then, the drying shrinkage decreased in the order of the 20\% CSAe sample shown in Figure $7 \mathrm{~b}$, and finally the $10 \%$ CSAe sample shown in Figure $7 \mathrm{a}$. As the substitution rate of CSAe increased, drying shrinkage tended to decrease. The $30 \%$ CSAe $+0 \%$ SF specimen showed fine cracks on the surface when measured after $28 \mathrm{~d}$ of aging. This cracking can be attributed to the excessive expansion caused by the high proportion of CSAe. However, cracks were not observed in the 5\% and 10\% SF specimens at the same $30 \%$ CSAe replacement ratio. Regardless of the rate of substitution of CSAe, there was a large variability in length variation from the early stage to $28 \mathrm{~d}$ of the measurement. However, after $28 \mathrm{~d}$, the variability of the length changes became smaller.

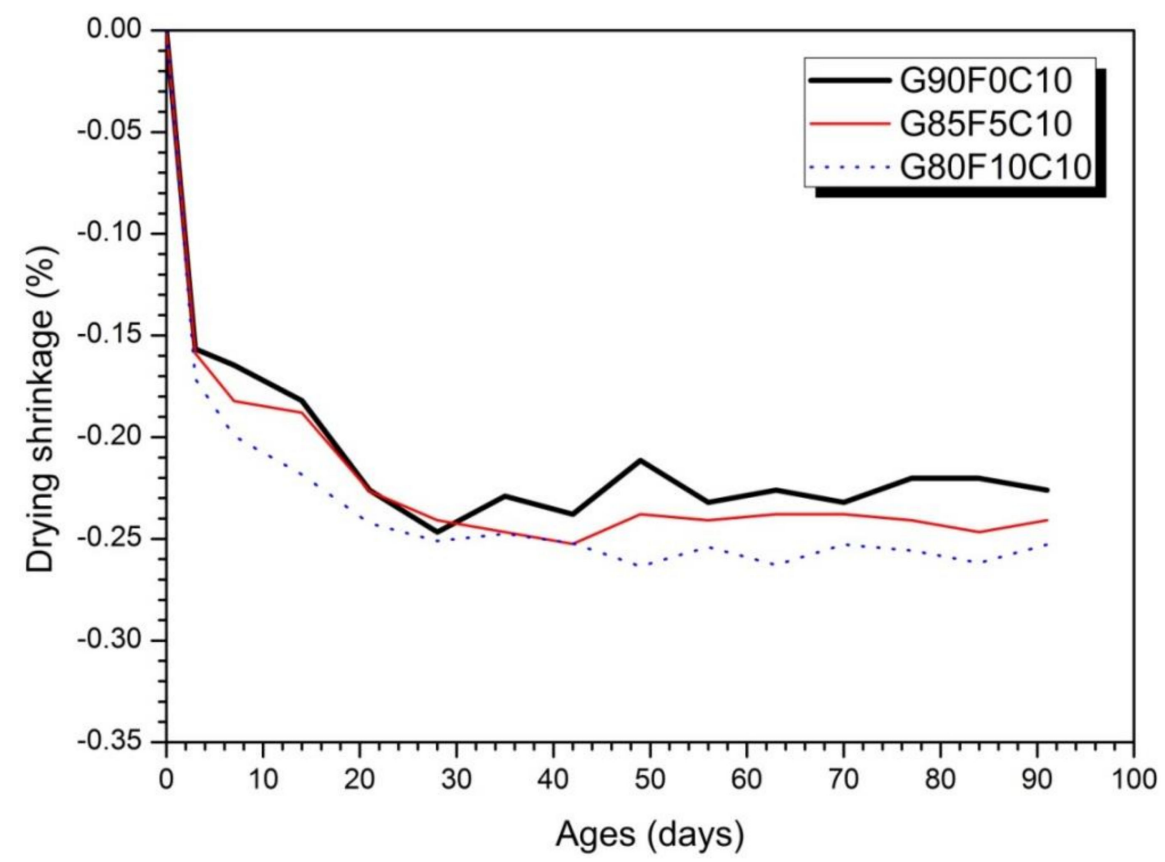

(a)

Figure 7. Cont. 


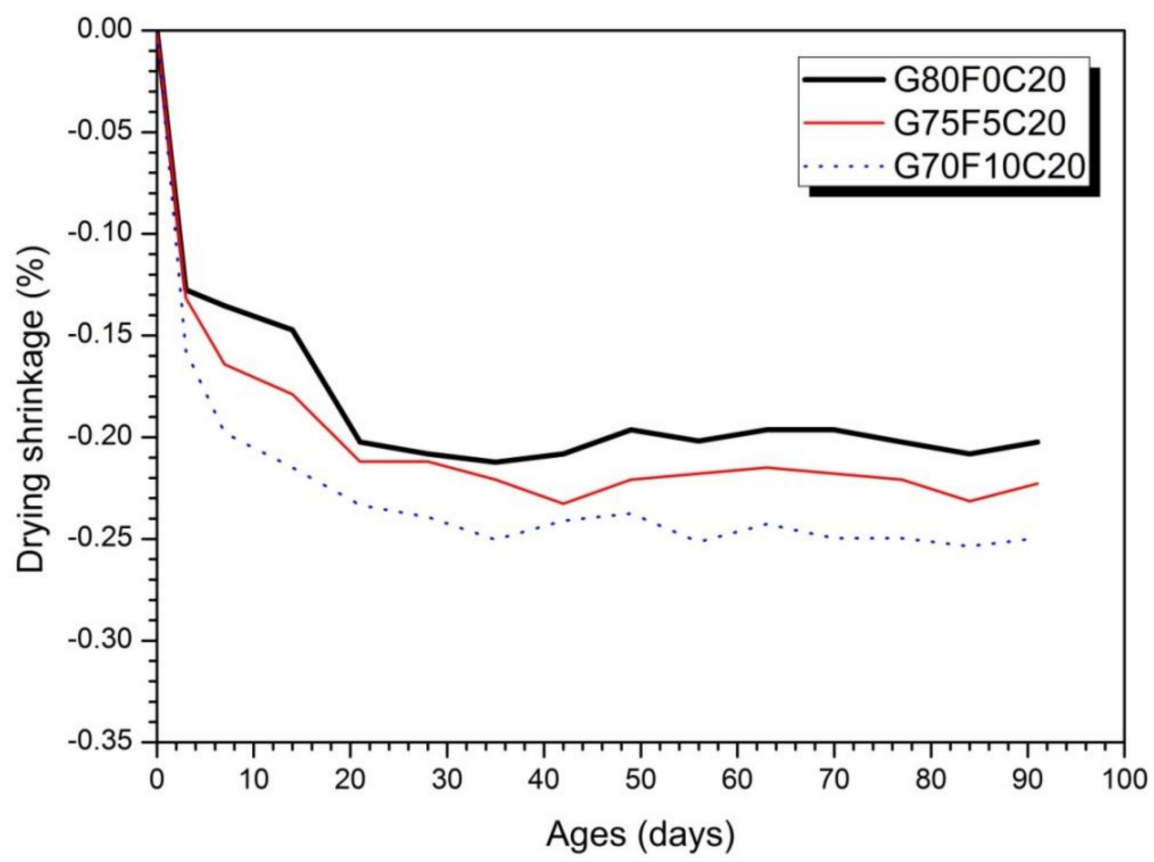

(b)

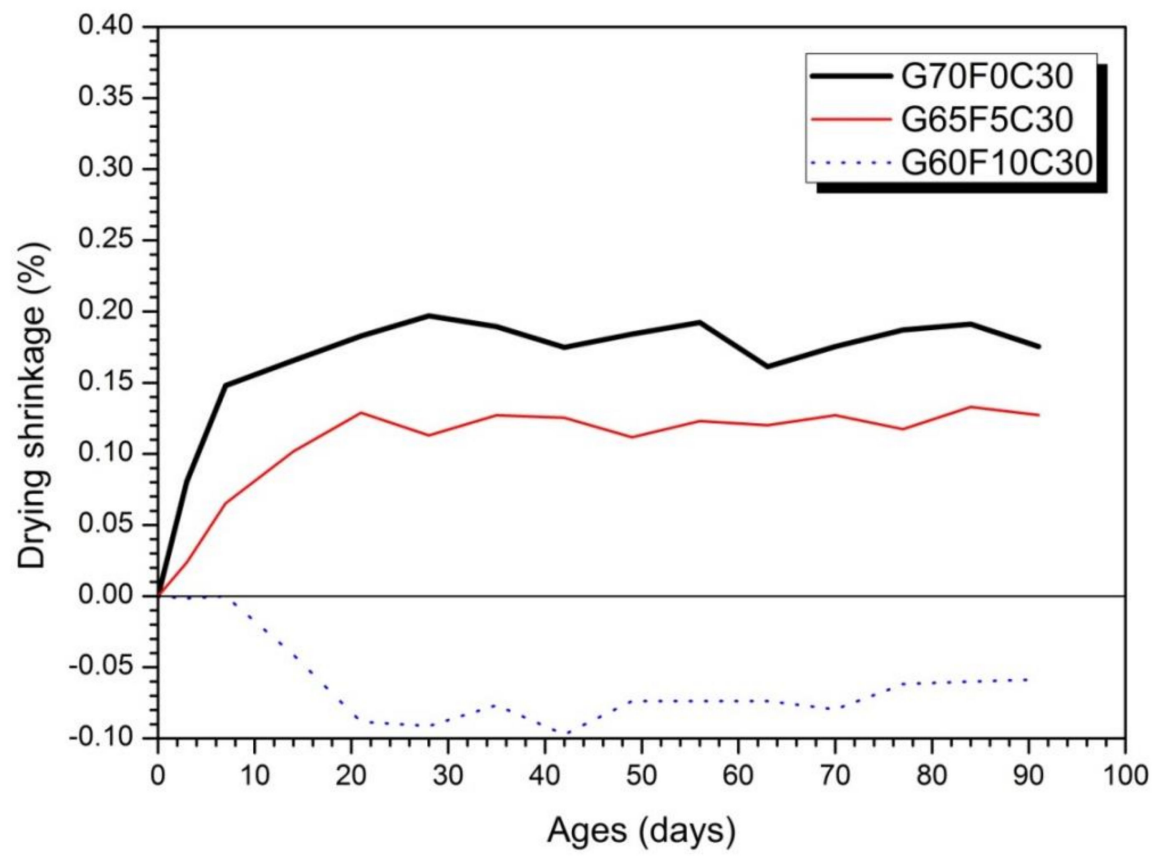

(c)

Figure 7. Drying shrinkage ratios, (a) 10\% CSAe, (b) 20\% CSAe, and (c) 30\% CSAe.

Chaunsali and Mondal [51] showed that, when CSA cement was substituted at $0 \%, 7 \%$, $15 \%$, and $30 \%$ in OPC, the specimen expanded as the CSA substitution rate increased. In particular, the $30 \%$ CSA sample showed cracking due to excessive expansion. In the current study, the 30\% CSAe samples showed the highest expansion rate (Figure 7c). This high expansion produced fine cracks on the sample surface and also affected the sample interior, resulting in a decrease in the compressive strength and a change in the pore structure.

The swelling effect of $\mathrm{C}_{6} \mathrm{AS}_{3} \mathrm{H}_{32}$ produced by $\mathrm{C}_{4} \mathrm{~A}_{3} \overline{\mathrm{S}}$ is most activated before $28 \mathrm{~d}$ of aging, which has a large effect on the reduction of drying shrinkage [42]. According to the results of Figure 7, the increase in the substitution ratio of CSAe increased the swelling 
and reduced the drying shrinkage. In previous studies, the shrinkage reduction effect was mentioned by the improvement of expandability due to the increase of CSA $[31,33,43]$.

As shown in Figure 7a, substitution of SF in the dry shrinkage graph of the $10 \%$ CSAe sample showed a tendency to increase the dry shrinkage. This is clearly observed as the substitution rate of SF increases. In addition, in Figure $7 \mathrm{~b}, \mathrm{c}$, where the substitution rates of CSAe are $20 \%$ and $30 \%$ CSAe, it can be seen that the effect of increasing drying shrinkage by substitution of SF is further promoted. That is, the drying shrinkage increased as the proportion of SF increased from $0 \%$ to $10 \%$ at the same CSAe replacement ratio. Drying shrinkage increases for three main reasons. First, the increase in drying shrinkage due to the substitution of SF is explained by the fineness of the SF particles and the resulting increase in surface area. A large amount of compounding is required because of the large surface area, and as a result, an insufficient amount of compounding is available for the hydration of $\mathrm{C}_{4} \mathrm{~A}_{3} \overline{\mathrm{S}}$. The presence of unhydrated $\mathrm{C}_{4} \mathrm{~A}_{3} \overline{\mathrm{S}}$, which is not fully hydrated, reduces expansion [5]. Second, the SF content reduces the $\mathrm{pH}$ of the pore solution, which slows down the hydration of $\mathrm{C}_{4} \mathrm{~A}_{3} \overline{\mathrm{S}}$ and decreases the expansion force [54]. Third, the reduction in drying shrinkage due to $\mathrm{SF}$ replacement is due to the reduction in pore size due to the filler effect of SF. This is because the capillary tension increased due to the reduced pores. [49,50]. The substitution of SF is effective in inhibiting the excessive swelling caused by the use of CSAe.

SF substitution increases the drying shrinkage but increases the compressive strength and decreases the size and number of pores. Therefore, it is necessary to control the amount of substitution of SF to control the compressive strength, pore structure, and drying shrinkage characteristics according to the purpose of use.

Previous studies have reported the re-expansion of $\mathrm{C}_{4} \mathrm{~A}_{3} \overline{\mathrm{S}}$ when water is supplied from the outside after the sample is cured [5]. Figure 3 shows that $\mathrm{C}_{4} \mathrm{~A}_{3} \overline{\mathrm{S}}$ increased with the substitution ratio of CSAe. Cracks were observed on the surface in the $30 \%$ CSAe sample. Therefore, the occurrence of cracks at the high CSAe replacement rate was due to the excessive expansion at the early age hydration stage and external water supply after curing.

\subsection{Thermal Analysis}

Figure 8 shows the results of the thermal analysis. In the temperature range of $30-180^{\circ} \mathrm{C}$, free water (interlayer water in the $\mathrm{C}-\mathrm{S}-\mathrm{H}$ gel), decomposition of ettringite/C$\mathrm{S}-\mathrm{H}[6,31,34]$, and a large amount of bound water were lost, resulting in weight loss. The weight loss around $500-750{ }^{\circ} \mathrm{C}$ was due to the decomposition of calcite $[16,25]$. As the amount of CSAe increased, the weight loss in the $30-180{ }^{\circ} \mathrm{C}$ range also increased. This may have been due to the increased formation of ettringite. In the XRD analysis results in Figure 3, the increase in the ettringite peak due to the increase in the substitution rate of CSAe is explained, and the thermal analysis supported this trend.

Regardless of the substitution rate of CSAe, the weight loss in the $30-180{ }^{\circ} \mathrm{C}$ temperature range increased as the substitution rate of SF increased to $0 \%, 5 \%$, and $10 \%$. The reason for the increased weight loss was that $\mathrm{SF}$ promoted the formation of ettringite or $\mathrm{C}-\mathrm{S}-\mathrm{H}$ gel. The weight loss in the $30-180{ }^{\circ} \mathrm{C}$ temperature range was the largest in the $30 \%$ CSAe samples (Figure 8e,f), followed by those in the 20\% CSAe (Figure 8c,d) and 10\% CSAe (Figure $8 \mathrm{a}, \mathrm{b}$ ) samples (in order of decreasing weight loss). The enhanced production of ettringite by the addition of SF improved the expansion force and reduced the drying shrinkage [54]. In addition, due to the filler effect of SF and the pore filling effect by ettringite, a dense matrix was formed, which partially contributed to the strength improvement. 


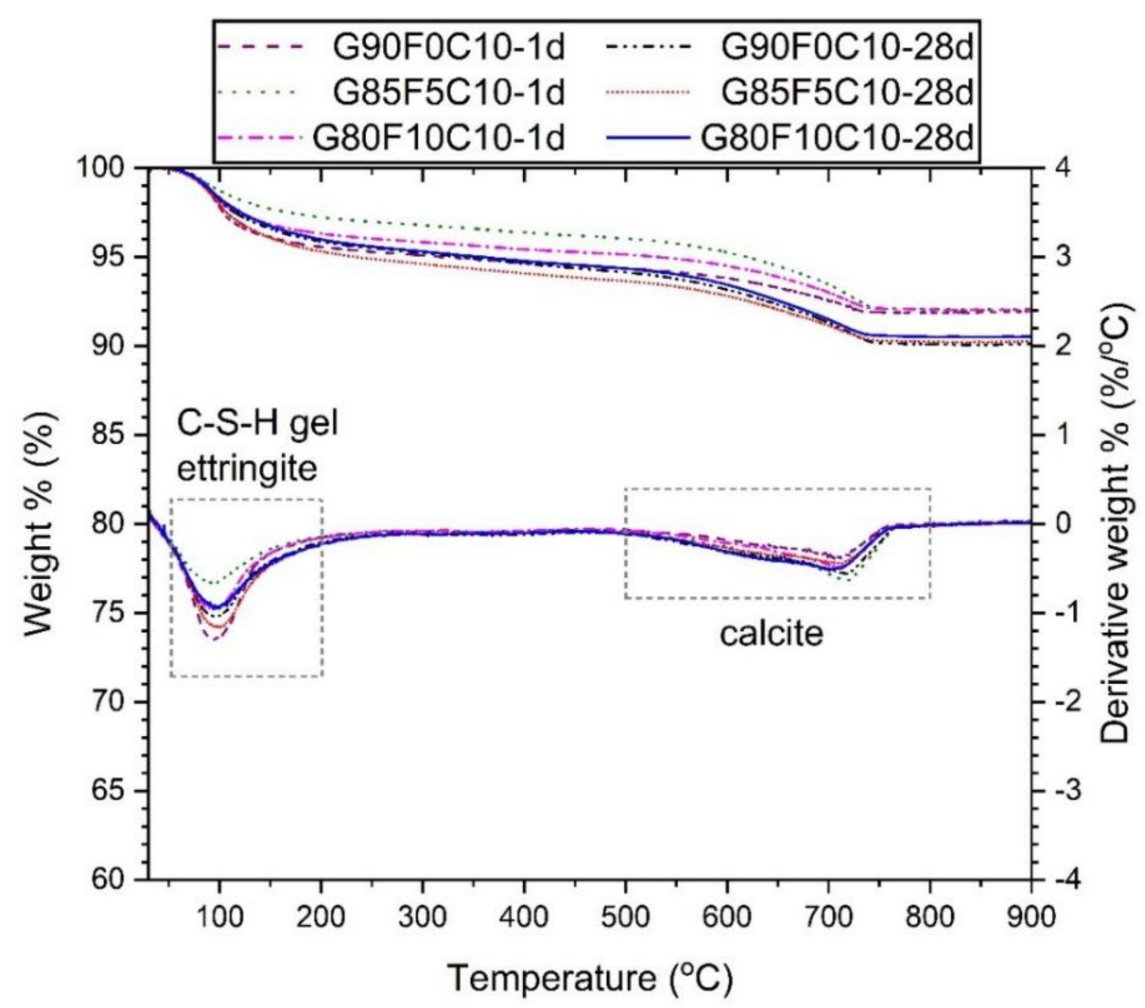

(a)

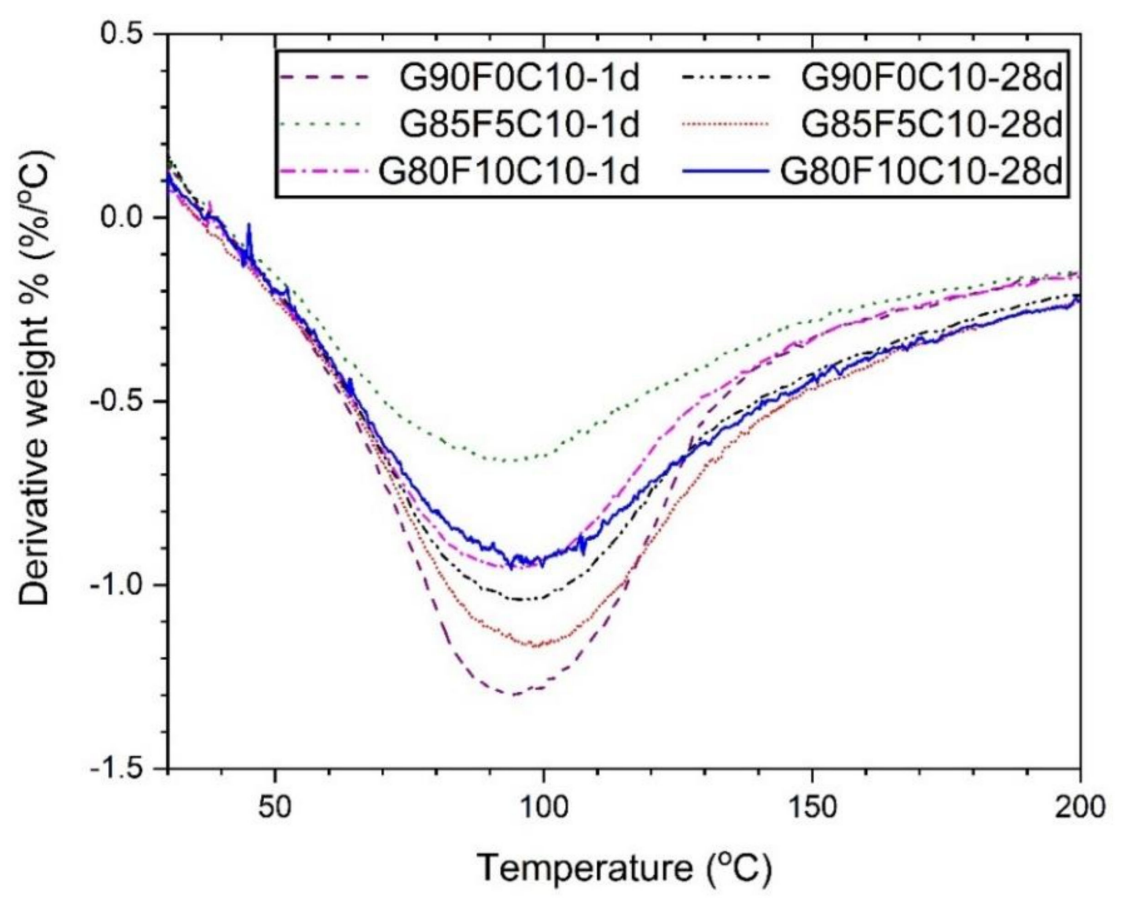

(b)

Figure 8. Cont. 


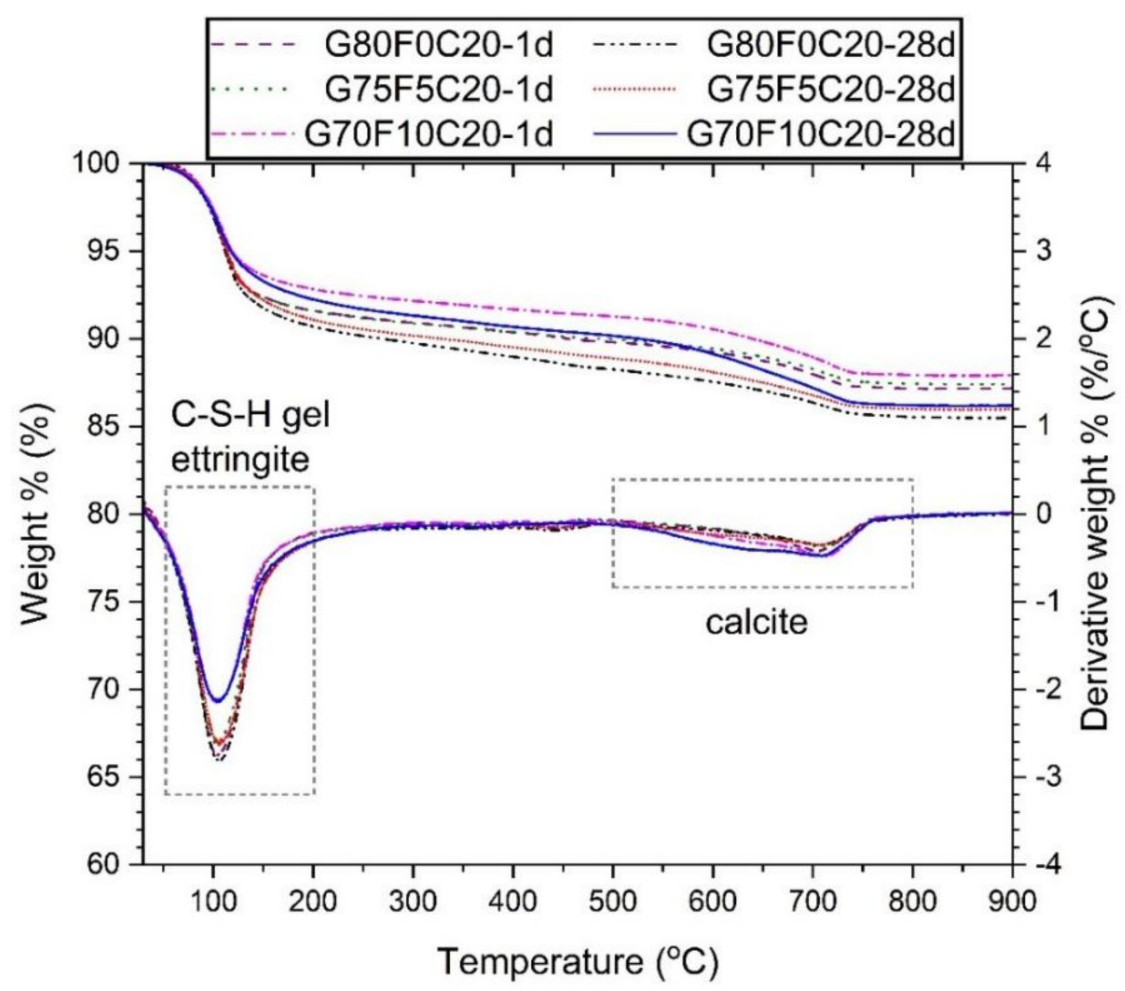

(c)

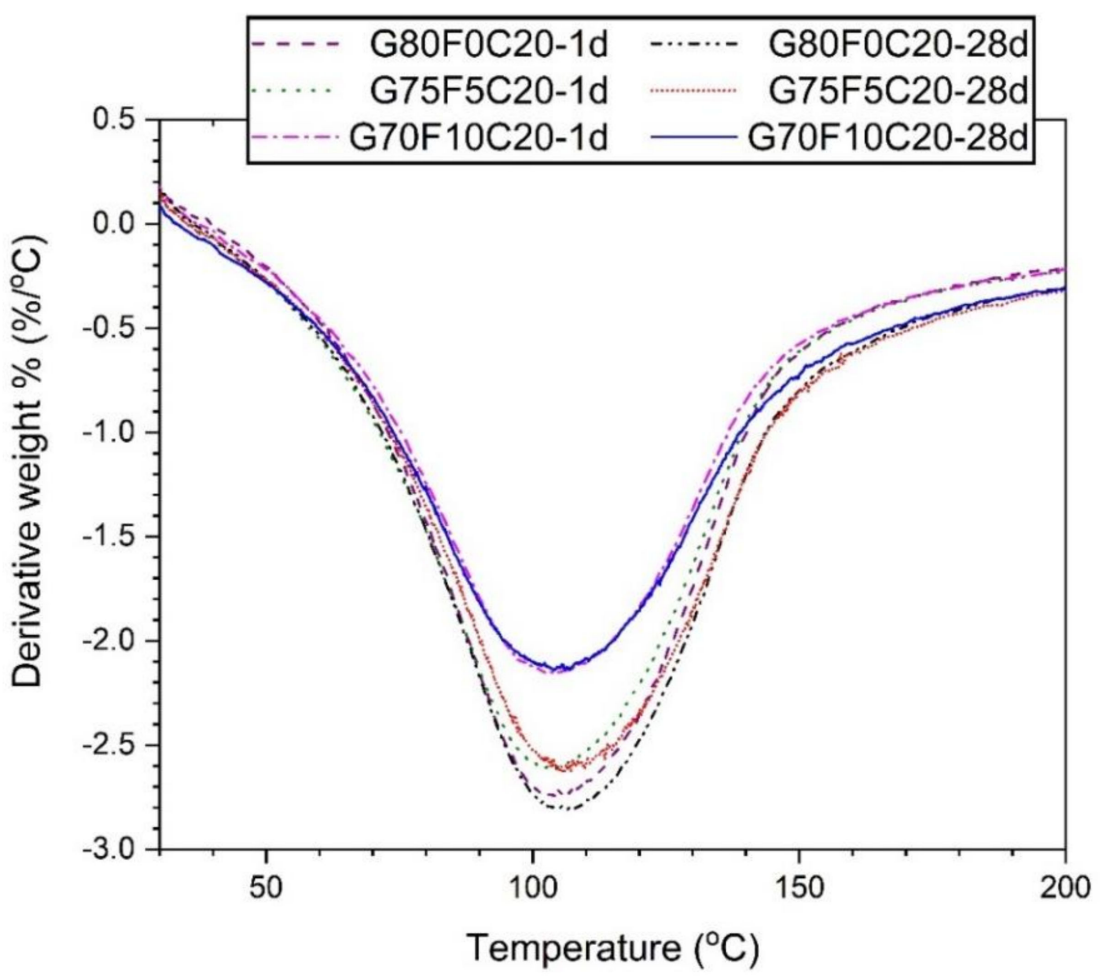

(d)

Figure 8. Cont. 


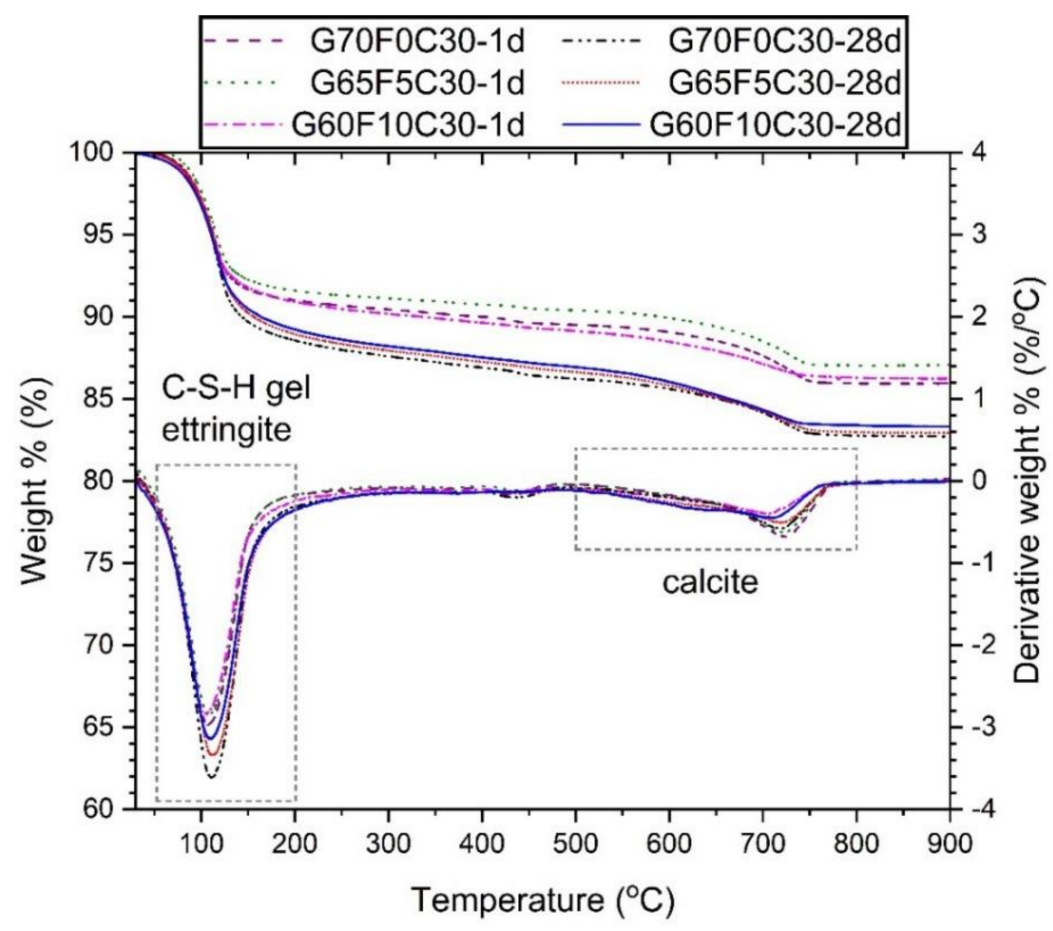

(e)

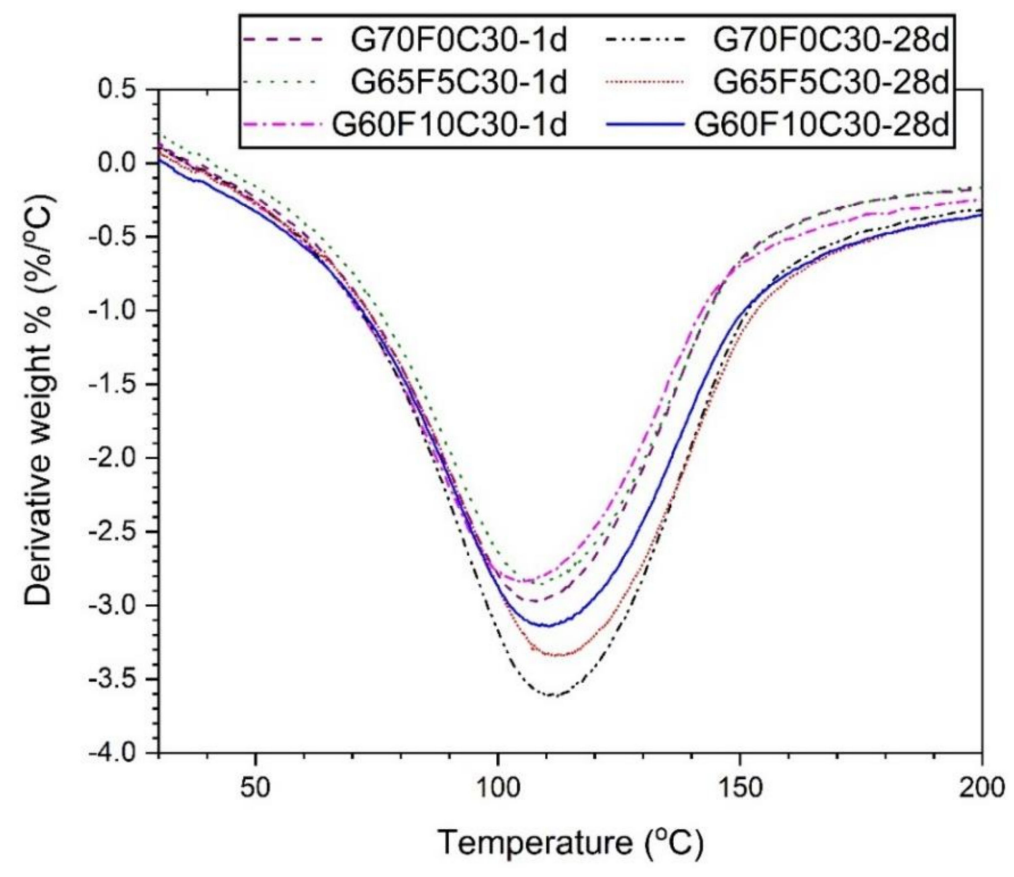

(f)

Figure 8. Thermal analysis (TG/DTG) at $1 \mathrm{~d}$ and $28 \mathrm{~d}$, (a) $10 \%$ CSAe samples, (b) $50-200{ }^{\circ} \mathrm{C}$ temperature range enlargement of 10\% CSAe samples, (c) 20\% CSAe sampless, (d) 50-200 ${ }^{\circ} \mathrm{C}$ temperature range enlargement of $20 \%$ CSAe samples, (e) 30\% CSAe samples, (f) 50-200 ${ }^{\circ} \mathrm{C}$ temperature range enlargement of $30 \%$ CSAe samples.

In Figure $8 b$, the weight loss ratio of $1 \mathrm{~d}$ was changed in the order of G90F0C10 > G80F10C10 > G85F5C10 and at 28d in the order of G85F5C10 > G90F0C10 > G80F10C10. In addition, as shown in Figure 8d, the weight loss ratio gradually decreases in the order of G80F0C20 > G75F5C20 > G70F10C20 in 1d and G80F0C20 > G75F5C20 > G70F10C20 in 
28d. In Figure 8f, the weight loss tends to change in the order of G70F0C30 > G65F5C30 > G60F10C30 when 1d and G70F0C30 > G65F5C30 > G60F10C30 when 28d. The weight loss observed in the region below 200 degrees Celsius is complex and unclear. This makes it difficult to distinguish clearly because hydration products are generated by SF and simple evaporation of moisture occurs at the same time [55,56]. Particularly, very fine particles of SF require a large amount of bound water [55-58]. Therefore, some of the water required for the hydration reaction of slag or CSAe particles is bound to the surface of the SF particles, which can be considered as an unclear cause of weight loss that hinders the hydration action.

\section{Conclusions}

The results of the mechanical performance test performed for the development of a low-carbon, eco-friendly cement comprising a mixture of CSAe, slag, and SF are summarized as follows:

(1) Regardless of the substitution rate of CSAe, $1 \mathrm{~d}$ showed a low value of $7 \mathrm{MPa}$ or less in all mixtures. However, the $28 \mathrm{~d}$ strength was at least $20 \mathrm{MPa}$ or more. This suggests that CSAe is insufficient for promoting the early age hydration stage of slag; additional methods are needed. The 30\% CSAe samples were lower than the $20 \%$ CSAe mixtures due to cracks and internal voids caused by excessive expansion. SF had a clear effect of improving the compressive strength. Therefore, the use of less than 30\% CSAe and SF can effectively improve the cement's compressive strength.

(2) The main hydration reactant was ettringite. In addition, as the content of CSAe increased, dehydrated ye'elimite also increased. Unlike in previous studies about OPC-based CSA cement, no other hydration products were observed in the slagCSAe-SF cement in the present work. Ettringite, a representative hydration product, was confirmed through XRD, SEM, and TG/DTG analyses. In addition, ettringite reduced the pore structure and the drying shrinkage. This was clearly seen as the substitution rate of CSAe increased.

(3) SF influences the improvement of compressive strength and controls the excessive expansion caused by CSAe. This is due to the very-fine-sized spherical particles with a high specific surface area of SF. The inhibition of the excessive expansion of SF was more evident in the $10 \%$ CSAe samples than in the 5\% CSAe mixtures.

The results of this study confirm that slag-CSAe-SF's low-carbon, ecofriendly cement can be used to manufacture cement that can produce structural concrete without using OPC. However, subsequent studies on early age strength improvement and durability are needed.

Author Contributions: Conceptualization, C.K. and T.K.; methodology, K.-Y.S. and T.K.; validation, C.K., K.-Y.S., and T.K.; formal analysis, T.K. and K.-Y.S.; investigation, C.K., T.-K.L. and K.-Y.S.; resources, C.K. and T.-K.L.; data curation, C.K. and T.K.; writing-original draft preparation, C.K. and T.K.; writing-review and editing, T.K.; visualization, T.K. and K.-Y.S.; supervision, T.K.; project administration, C.K. and T.K.; funding acquisition, C.K. All authors have read and agreed to the published version of the manuscript.

Funding: This work was supported by the National Research Foundation of Korea (NRF) grant funded by the Korean Government (MOE) (NRF-2020R1I1A1A01056497).

Institutional Review Board Statement: Not applicable.

Informed Consent Statement: Not applicable.

Data Availability Statement: Not applicable.

Acknowledgments: The authors thank the Core Research Facility of Pusan National University funded by the Korea Ministry of Education for the technical support on XRD, SEM, TG/DTG analysis.

Conflicts of Interest: The authors declare no conflict of interest. 


\section{References}

1. Juenger, M.C.G.; Winnefeld, F.; Provis, J.L.; Ideker, J.H. Advances in alternative cementitious binders. Cem. Concr. Res. 2011, 41, 1232-1243. [CrossRef]

2. Chen, I.A.; Hargis, C.W.; Juenger, M.C.G. Understanding expansion in calcium sulfoaluminate-Belite cements. Cem. Concr. Res. 2012, 42, 51-60. [CrossRef]

3. Wang, W.; Wang, X.; Zhu, J.; Wang, P.; Ma, C. Experimental investigation and modeling of sulfoaluminate cement preparation using desulfurization gypsum and red mud. Ind. Eng. Chem. Res. 2013, 52, 1261-1266. [CrossRef]

4. Wu, K.; Shi, H.; Guo, X. Utilization of municipal solid waste incineration fly ash for sulfoaluminate cement clinker production. Waste Manag. 2011, 31, 2001-2008. [CrossRef] [PubMed]

5. Glasser, F.P.; Zhang, L. High-performance cement matrices based on calcium sulfoaluminate-belite compositions. Cem. Concr. Res. 2001, 31, 1881-1886. [CrossRef]

6. Winnefeld, F.; Lothenbach, B. Calorimetric and thermogravimetric study on the influence of calcium sulfate on the hydration of ye'elimite. J. Therm. Anal. Calorim. 2010, 101, 949-957. [CrossRef]

7. Pacheco-Torgal, F.; Jalali, S.; Labrincha, J.; John, V.M. Eco-efficient Concrete; Woodhead Publishing: Oxford, UK, $2014 ;$ pp. 488-515.

8. Pelletier, L.; Winnefeld, F.; Lothenbach, B. The ternary system Portland cementcalcium sulphoaluminate clinker-anhydrite: Hydration mechanism and mortar properties. Cem. Concr. Compos. 2010, 32, 497-507. [CrossRef]

9. Cheung, A.K.; Leung, C.K. Shrinkage reduction of high strength fiber reinforced cementitious composites (HSFRCC) with various water-to-binder ratios. Cement Concr. Compos. 2011, 33, 661-667. [CrossRef]

10. Soliman, A.M.; Nehdi, M.L. Effect of drying conditions on autogenous shrinkage in ultra-high performance concrete at early-age. Mater. Struct. 2011, 44, 879-899. [CrossRef]

11. Yu, J.; Li, H.; Leung, C.K.; Lin, X.; Lam, J.Y.; Sham, I.M.; Shih, K. Matrix design for waterproof engineered cementitious composites (ECCs). Constr. Build. Mater. 2017, 139, 438-446. [CrossRef]

12. Li, N.; Xu, L.; Wang, R.; Li, L.; Wang, P. Experimental study of calcium sulfoaluminate cement-based self-leveling compound exposed to various temperatures and moisture conditions: Hydration mechanism and mortar properties. Cem. Concr. Res. 2018, 108, 103-115. [CrossRef]

13. Sirtoli, D.; Wyrzykowski, W.; Riva, P.; Tortelli, S.; Marchi, M.; Lura, P. Shrinkage and creep of high-performance concrete based on calcium sulfoaluminate cement. Cem. Concr. Compos. 2019, 98, 61-73. [CrossRef]

14. Mehdipour, I.; Khayat, K.H. Enhancing the performance of calcium sulfoaluminate blended cements with shrinkage reducing admixture or lightweight sand. Cem. Concr. Compos. 2018, 87, 29-43. [CrossRef]

15. Chen, Y.; Yao, J.; Lu, Z.; Leung, C.K.Y. Experimental study on the shrinkage reduction of high strength strain hardening cementitious composites. Cem. Concr. Compos. 2019, 104, 103416. [CrossRef]

16. Shen, P.; Lu, L.; He, Y.; Wang, F.; Lu, J.; Zheng, H.; Hu, S. Investigation on expansion effect of the expansive agents in ultra-high performance concrete. Cem. Concr. Compos. 2020, 105, 103425. [CrossRef]

17. Zhang, J.; Li, G.; Ye, W.; Chang, Y.; Liu, Q.; Song, Z. Effects of ordinary Portland cement on the early properties and hydration of calcium sulfoaluminate cement. Constr. Build. Mater. 2018, 186, 1144-1153. [CrossRef]

18. Zhang, J.; Ye, C.; Tan, H.; Liu, X. Potential application of Portland cement-sulfoaluminate cement system in precast concrete cured under ambient temperature. Constr. Build. Mater. 2020, 251, 118869. [CrossRef]

19. Li, L.; Wang, R.; Zhang, S. Effect of curing temperature and relative humidity on the hydrates and porosity of calcium sulfoaluminate cement. Constr. Build. Mater. 2019, 213, 627-636. [CrossRef]

20. Zhang, Y.; Chang, J.; Ji, J. $\mathrm{AH}_{3}$ phase in the hydration product system of AFt-AFm- $\mathrm{AH}_{3}$ in calcium sulfoaluminate cements: A microstructural study. Constr. Build. Mater. 2018, 167, 587-596. [CrossRef]

21. Jeong, Y.; Hargis, C.W.; Chun, S.C.; Moon, J. The effect of water and gypsum content on strätlingite formation in calcium sulfoaluminate-belite cement pastes. Constr. Build. Mater. 2018, 166, 712-722. [CrossRef]

22. Tambara Jr, L.U.D.; Cheriaf, M.; Rocha, J.C.; Palomo, A.; Fernández-Jiménez, A. Effect of alkalis content on calcium sulfoaluminate (CSA) cement hydration. Cem. Concr. Res. 2020, 128, 105953. [CrossRef]

23. Ke, G.; Zhang, J.; Xie, S.; Pei, T. Rheological behavior of calcium sulfoaluminate cement paste with supplementary cementitious materials. Constr. Build. Mater. 2020, 243, 118234. [CrossRef]

24. Yeung, J.S.K.; Yam, M.C.H.; Wong, Y.L. 1-Year development trend of concrete compressive strength using Calcium Sulfoaluminate cement blended with OPC, PFA and GGBS. Constr. Build. Mater. 2019, 198, 527-536. [CrossRef]

25. Mobili, A.; Telesca, A.; Marroccoli, M.; Tittarelli, F. Calcium sulfoaluminate and alkali-activated fly ash cements as alternative to Portland cement: Study on chemical, physical-mechanical, and durability properties of mortars with the same strength class. Constr. Build. Mater. 2020, 246, 118436. [CrossRef]

26. Frank, W.; Barbara, L. Hydration of calcium sulphoaluminate cementseexperimental findings and thermodynamic modeling. Cem. Concr. Res. 2010, 40, 1239-1247.

27. Jun, Y.; Kim, J.H.; Kim, T. Hydration of calcium sulfoaluminate-based binder incorporating red mud and silica fume. Appl. Sci. 2019, 9, 2270. [CrossRef]

28. ASTM International. Standard Practice for Mechanical Mixing of Hydraulic Cement Pastes and Mortars of Plastic Consistency; ASTM C305; ASTM International: West Conshohocken, PA, USA, 2014. 
29. ASTM International. Standard Test Method for Compressive Strength of Hydraulic Cement Mortars (Using 2-in. or [50-mm] Cube Specimens); ASTM C109; ASTM International: West Conshohocken, PA, USA, 2016.

30. ASTM International. Standard Test Method for Drying Shrinkage of Mortar Containing Hydraulic Cement; ASTM C596: West Conshohocken, PA, USA, 2009.

31. Michel, M.; Georgin, J.-F.; Ambroise, J.; Péra, J. The influence of gypsum ratio on the mechanical performance of slag cement accelerated by calcium sulfoaluminate cement. Constr. Build. Mater. 2011, 25, 1298-1304. [CrossRef]

32. Trauchessec, R.; Mechling, J.-M.; Lecomte, A.; Roux, A.; Le Rolland, B. Hydration of ordinary Portland cement and calcium sulfoaluminate cement blends. Cem. Concr. Compos. 2015, 56, 106-114. [CrossRef]

33. Han, J.; Jia, D.; Yan, P. Understanding the shrinkage compensating ability of type K expansive agent in concrete. Constr. Build. Mater. 2016, 116, 36-44. [CrossRef]

34. Le Saoût, G.; Lothenbach, B.; Hori, A.; Higuchi, T.; Winnefeld, F. Hydration of Portland cement with additions of calcium sulfoaluminates. Cem. Concr. Res. 2013, 43, 81-94. [CrossRef]

35. Tan, H.; Li, M.; He, X.; Su, Y.; Zhang, J.; Pan, H.; Yang, J.; Wang, Y. Preparation for micro-lithium slag via wet grinding and its application as accelerator in Portland cement. J. Clean. Prod. 2020, 250, 119528. [CrossRef]

36. Qin, L.; Gao, X.; Zhang, A. Potential application of Portland cement-calcium sulfoaluminate cement blends to avoid early age frost damage. Constr. Build. Mater. 2018, 190, 363-372. [CrossRef]

37. Tang, S.W.; Zhu, H.G.; Li, Z.J.; Chen, E.; Shao, H.Y. Hydration stage identification and phase transformation of calcium sulfoaluminate cement at early age. Constr. Build. Mater. 2015, 75, 11-18. [CrossRef]

38. Minard, H.; Garrault, S.; Regnaud, L.; Nonat, A. Mechanisms and parameters controlling the tricalcium aluminate reactivity in the presence of gypsum. Cem. Concr. Res. 2007, 37, 1418-1426. [CrossRef]

39. Rao, G.A. Long-term drying shrinkage of mortar-Influence of silica fume and size of fine aggregate. Cem. Concr. Res. 2001, 31, 171-175. [CrossRef]

40. Rao, G.A. Role of water-binder ratio on the strength development in mortars incorporated with silica fume. Cem. Concr. Res. 2001, 31, 443-447. [CrossRef]

41. Winnefeld, F.; Martin, L.H.J.; Muller, C.J.; Lothenbach, B. Using gypsum to control hydration kinetics of CSA cements. Constr. Build. Mater. 2017, 155, 154-163. [CrossRef]

42. Hargis, C.W.; Kirchheim, A.P.; Monteiro, P.J.M.; Gartner, E.M. Early age hydration of calcium sulfoaluminate (synthetic ye'elimite, $\mathrm{C}_{4} \mathrm{~A}_{3} \bar{S}$ ) in the presence of gypsum and varying amounts of calcium hydroxide. Cem. Concr. Res. 2013, 48, 105-115. [CrossRef]

43. Ioannou, S.; Reig, L.; Paine, K.; Quillin, K. Properties of a ternary calcium sulfoaluminate-calcium sulfate-fly ash cement. Cem. Concr. Res. 2014, 56, 75-83. [CrossRef]

44. Ioannou, S.; Paine, K.; Reig, L.; Quillin, K. Performance characteristics of concrete based on a ternary calcium sulfoaluminateanhydrite-fly ash cement. Cem. Concr. Compos. 2015, 55, 196-204. [CrossRef]

45. García-Maté, M.; De la Torre, A.G.; León-Reina, L.; Aranda, M.A.G.; Santacruz, I. Hydration studies of calcium sulfoaluminate cements blended with fly ash. Cem. Concr. Res. 2013, 54, 12-20. [CrossRef]

46. Cook, R.A.; Hover, K.C. Mercury porosimetry of hardened cement pastes. Cem. Concr. Res. 1999, 29, 933-943. [CrossRef]

47. Diamond, S. Mercury porosimetry: An inappropriate method for the measurement of pore size distributions in cement-based materials. Cem. Concr. Res. 2000, 30, 1517-1525. [CrossRef]

48. Bernardo, G.; Telesca, A.; Valenti, G.L. A porosimetric study of calcium sulfoaluminate cement pastes cured at early ages. Cem. Concr. Res. 2006, 36, 1042-1047. [CrossRef]

49. Chaunsali, P.; Mondal, P. Physico-chemical interaction between mineral admixtures and OPC-calcium sulfoaluminate (CSA) cements and its influence on early-age expansion. Cem. Concr. Res. 2016, 80, 10-20. [CrossRef]

50. Mazloom, M.; Ramezanianpour, A.A.; Brooks, J.J. Effect of silica fume on mechanical properties of high-strength concrete. Cem. Concr. Compos. 2004, 26, 347-357. [CrossRef]

51. Chaunsali, P.; Monda, P.L. Influence of calcium sulfoaluminate (CSA) cement content on expansion and hydration behavior of various ordinary Portland cement-CSA blends. J. Am. Ceram. Soc. 2015, 98, 2617-2624. [CrossRef]

52. García-Maté, M.; Londono-Zuluaga, D.; de la Torre, A.G.; Losilla, E.R.; Cabeza, A.; Aranda, M.A.G.; Santacruz, I. Tailored setting times with high compressive strengths in bassanite calcium sulfoaluminate eco-cements. Cem. Concr. Compos. 2016, 72, 39-47. [CrossRef]

53. Telesca, A.; Marroccoli, M.; Pace, M.L.; Tomasulo, M.; Valenti, G.L.; Monteiro, P.J.M. A hydration study of various calcium sulfoaluminate cements. Cem. Concr. Compos. 2014, 53, 224-232. [CrossRef]

54. Lobo, C.; Cohen, M.D. Hydration of Type K expansive cement paste and the effect of silica fume: I. Expansion and solid phase analysis. Cem. Concr. Res. 1992, 22, 961-969. [CrossRef]

55. Gao, X.; Yu, Q.L.; Brouwers, H.J.H. Characterization of alkali activated slag-fly ash blends containing nano-silica. Constr. Build. Mater. 2015, 98, 397-406. [CrossRef]

56. Gao, K.; Lin, K.-L.; Wang, D.Y.; Hwang, C.-L.; Tuan, B.L.A.; Shiu, H.-S.; Cheng, T.-W. Effect of nano-SiO2 on the alkali-activated characteristics of metakaolin-based geopolymers. Constr. Build. Mater. 2013, 48, 441-447. [CrossRef] 
57. Qing, Y.; Zenan, Z.; Deyu, K.; Rongshen, C. Influence of nano-SiO2 addition on properties of hardened cement paste as compared with silica fume. Constr. Build. Mater. 2007, 21, 539-545. [CrossRef]

58. Senff, L.; Labrincha, J.A.; Ferreira, V.M.; Hotza, D.; Repette, W.L. Effect of nano-silica on rheology and fresh properties of cement pastes and mortars. Constr. Build. Mater. 2009, 23, 2487-2491. [CrossRef] 